\title{
Evidence that $\pi$-Ligand Exchange Reactions of Chalcogen Iranium Ions Proceed via Hückel Pseudocoarctate Transition States
}

\author{
Samuel C. Brydon ${ }^{\mathrm{a}^{*}}$, Gabriel da Silva ${ }^{\mathrm{b}}$, Jonathan M. White $\mathrm{a}^{\mathrm{a}^{*}}$ \\ a School of Chemistry and Bio21 Institute, The University of Melbourne, Parkville, Victoria 3010, \\ Australia. \\ ${ }^{\mathrm{b}}$ Chemical Engineering, The University of Melbourne, Parkville, Victoria 3010, Australia.
}

Email:

brydons@student.unimelb.edu.au

whitejm@unimelb.edu.au

\begin{abstract}
Despite numerous computational and experimental studies on the $\pi$-ligand exchange reactions of chalcogen iranium ions, a classification of the reaction class has yet to be made. The characteristics of the transition states presented thus far suggested a coarctate nature with two bonds breaking and forming simultaneously at the chalcogen centre. The change in barrier height, depending on the nature of the chalcogen and the alkene, was initially attributed as a shift in the degree of aromaticity moving from pseudocoarctate to coarctate reactions. However, this paper suggests that all twelve reactions under consideration are pseudocoarctate with a Hückel number of delocalised $\pi$ electrons based on comprehensive studies of the orbital interactions and magnetic properties both at the transition state and along the reaction path. The change in barrier height was largely driven by the electrophilicity of the chalcogen and the strain present in the three-membered ring, rather than a shift in the degree of aromaticity.
\end{abstract}

This is the author manuscript accepted for publication and has undergone full peer review but has not been through the copyediting, typesetting, pagination and proofreading process, which may lead to differences between this version and the Version of Record. Please cite this article as doi: $10.1002 /$ poc. 4111

This article is protected by copyright. All rights reserved. 


\section{Introduction}

Chalcogen $(\mathrm{Ch})$ iranium ions of general structure $\mathbf{1}$ have been shown to be important reactive intermediates in a variety of transformations, particularly in the functionalisation of alkenes, ${ }^{1-9}$ and have been structurally characterised by both NMR and crystallographic techniques. ${ }^{10-12}$ In stereoselective syntheses, neighbouring group participation by the chalcogen ensures stereochemical integrity is maintained in products $\mathbf{2}$ or $\mathbf{2}$ ' following ring opening by either an inter- or intramolecular nucleophile (Path A, Scheme 1) ${ }^{2,13-15}$ Racemisation may occur by several pathways including ring opening of the intermediate followed by bond rotation (Path B, Scheme 1), or $\pi$-ligand exchange reactions involving two distinct mechanisms. ${ }^{8,12,16-18}$ The dissociative pathway has been controlled by utilising dry, noncoordinating solvents and non-nucleophilic counterions to avoid production of an electrophilic transfer reagent $\mathbf{3}$ between alkenes (Path $\mathbf{C}$ and Path $\mathbf{D}$, Scheme 1). ${ }^{11,12}$ The associative pathway, involving attack at the electrophilic chalcogen by another alkene equivalent, has been studied by Denmark et al. in solution by generating both thiiranium and seleniranium ions in situ and shown to be feasible for all reactions studied where there was a thermodynamic driving force (Path E, Scheme 1). ${ }^{12}$ Studies on the stereoselective outcomes of reactions that proceed via these intermediates have shown this latter pathway may also be suppressed by suitably sterically bulky (e.g. 2,4,6-tri-tert-butylphenyl) or electron withdrawing groups (e.g. o-nitrophenyl) on the chalcogen (Path E, Scheme 1). ${ }^{7,19-21}$ Though these racemisation pathways are less important for thiiranium ions, they are significant in the more electrophilic seleniranium ions and telluriranium ions and the nature of their mechanism warrants further investigation.

Recent experimental studies into cyclisations have highlighted the fact that the associative mechanism of $\pi$-ligand exchange may be exploited in synthesis rather than merely being an undesirable side reaction. ${ }^{22}$ Continuing from similar utilisation of bromiranium salts, ${ }^{23}$ Bock et al. have used both adamantyl (Ad) derived thiiranium and seleniranium ion salts to induce polyene type cyclisations via associative transfer of the chalcogen moiety with the diastereoselectivity in the product $\mathbf{6}$ dictated by the Eschenmoser-Stork postulate (Scheme 2). ${ }^{11}$ The yields increased in the order $n$-BuSe${ }^{+}<\mathrm{PhS}^{+}<$ $\mathrm{PhSe}$ reflecting the influence of both the $\mathrm{R}$ group and the nature of the chalcogen on the extent of the transfer. These studies have prompted further investigation into the stereoelectronic factors governing the mechanism of this associative transfer.

To avoid potential dissociative transfer facilitated by solvents, counter ions and impurities, studies in the gas phase have investigated both the thermodynamic and kinetic factors controlling associative transfer (or lack thereof) of $\mathrm{PhS}^{+}, \mathrm{PhSe}^{+}$and $\mathrm{PhTe}^{+}$moieties between alkenes (Scheme 3) ${ }^{24-26}$ Structures of the iranium ions $\mathbf{2 7 - 2 8}$ in particular, produced by electrospray ionisation (ESI) of appropriate precursors 25-26, were supported by high-resolution mass spectrometry (HRMS), infrared multiple photon dissociation (IRMPD) and density functional theory (DFT) calculations with little if any isomerisation to the related onium ions occurring. ${ }^{24,25}$ Thiiranium ions 10, 19, and 27 were not observed to undergo transfer in the gas phase and instead produced an electrophilic addition product, contrasting with experiments by Denmark et al. which suggest this transfer is feasible in the solution phase. ${ }^{12}$ Where there was a thermodynamic driving force, the $\mathrm{PhSe}^{+}$moiety was transferred between alkenes in ionmolecule reactions (IMR) (28 to 30), but identity exchange reactions suggested that the intrinsic kinetic barrier could also dominate reaction outcomes (11 to 14 compared to 20 to 23 ). Both telluriranium ions 12 and 21 readily underwent associative $\pi$-ligand exchange reflecting the greater electrophilicity of this chalcogen atom. DFT calculations suggested that the identity exchange of $\mathbf{2 1}$ to $\mathbf{2 4}$ is effectively barrierless in the gas phase as, though a transition state was identified for this reaction, its energy was so low compared to the ion-neutral complex that the barrier vanished once zero point vibrational energy corrections were applied. ${ }^{26}$ 
Despite these insights, no studies have determined the nature of the transition states of associative $\pi$ ligand exchange of chalcogen iranium ions. Previous computational work has shown that there are two significant orbital interactions, ${ }^{18}$ with donation of the $\pi$ orbitals of the alkenes into a vacant $\mathrm{p}^{+}$orbital on the chalcogen and a weaker back-bonding of the chalcogen p-type lone pair into the $\pi^{*}$ orbitals of the alkenes, analogous to $\pi$ back-bonding in metal complexes with alkene ligands (Figure 1). ${ }^{27}$ These interactions dictate the coplanar orientation of the $\pi$ orbitals of the alkenes at the transition state to ensure optimal orbital overlap, leading to comparisons in the topology to the triple ion configuration in $\mathrm{S}_{\mathrm{N}} 2$ reactions $\left(\mathrm{X}^{-} \cdots \mathrm{CH}_{3}{ }^{+} \cdots \mathrm{X}^{-}\right)$. At first, the concomitant bond breaking and forming may suggest a transition state of pericyclic nature. However, pericyclic reactions involve one bond breaking and forming per atom, whilst in this case there are each two bonds breaking and forming at the central chalcogen suggesting these transition states may instead be coarctate in nature.

Coarctate transition states have been determined as topologically equivalent to pericyclic transition states (homeomorphous), thus the same Hückel and Möbius rules may be applied to determine aromaticity or antiaromaticity (or lack thereof in pseudopericyclic transition states) may be applied to coarctate transition states as well. ${ }^{28,29}$ Herges has shown that coarctate reactions with $4 n+2 \pi$ electrons (Hückel) exhibit coplanar loops, whilst reactions with $4 n \pi$ electrons (Möbius) exhibit orthogonal loops. ${ }^{29,30}$ An electron count of the $\pi$-ligand exchange transition states reveals a total of $6 \pi$ electrons involved $\left(2 \times \pi_{\mathrm{C}=\mathrm{C}}\right.$ and $1 \times \mathrm{n}_{\mathrm{Ch}}$, i.e. $\left.4 n+2\right)$, suggesting potential Hückel aromaticity. Application of group theory has been used to discriminate between pseudo and true pericyclic and coarctate transition states, as there must be distortion in the orbital arrangement (e.g. $\mathrm{C}_{2}$ symmetry) to ensure there are no disconnections in the latter. However, a high symmetry point group in the molecule (e.g. $\mathrm{D}_{2 \mathrm{~h}}$ ), particularly in the plane where the bond breaking and forming is occurring, suggests some level of disconnection in the orbital loop and hence these transition states are more likely pseudopericyclic or pseudocoarctate in nature. ${ }^{30}$

\section{Computational Methods}

Density functional theory (DFT) calculations were carried out with the Gaussian 16 revision B.01 software package. ${ }^{31}$ Geometries were optimised using the hybrid meta-GGA functional M06-2X and the def2-TZVP basis set, ${ }^{32,33}$ which has been used previously for the study of chalcogen iranium ions and provided theoretical rates in excellent agreement with gas phase experiments. ${ }^{25,26}$ The M06-2X functional is suitable for main group thermochemistry with reliability across a range of data sets compared to other DFT methods, ${ }^{34}$ and similar functionals (M05-2X) have accurately predicted the structure of asymmetric oxiranium ions compared to the high-level coupled-cluster CCSD method. ${ }^{35}$ Zero-point vibrational energy (ZPVE) corrections for electronic energies were obtained using unscaled harmonic vibrational frequencies. Transition states were confirmed by frequency analysis (one imaginary frequency) and connected to the intermediates by intrinsic reaction coordinate (IRC) calculations. Unless otherwise noted, energies in the text include ZPVE corrections and are at $0 \mathrm{~K}$. The reaction energy $(\Delta E)$ has been noted by Dau et al as the pertinent thermodynamic parameter to describe low pressure bimolecular reactions and as such has been used in this study. ${ }^{36}$ Cartesian coordinates for all calculated structures as well as enthalpies and Gibbs energies $(298 \mathrm{~K})$ are available in the Supporting Information. Natural bond orbital (NBO) analysis of transition states and selected reaction coordinates was conducted with NBO 7.0 developed by Glendening and co-workers, ${ }^{37}$ and orbitals visualised with Avogadro version 1.2.0. ${ }^{38}$ Stabilisation energies were obtained by deletions analysis through removal of individual significant orbital interactions in the NBO program interfaced with Gaussian 16 (see text for further information) ${ }^{39}$ Points along the reaction coordinate (obtained from IRC calculations) were examined by NBO, whilst the magnetic properties were monitored by changes in the anisotropy of the magnetic susceptibility $\left(\chi_{\text {anis }}\right)$ calculated using the individual gauges for atoms in molecules (IGAIM) 
method. ${ }^{40}$ Further information about the electron delocalisation at the transition state was obtained by analysing the anisotropy of the induced current density (ACID) calculated using the ACID program provided by the Herges research group.$^{41}$ The current densities were calculated using the continuous set of gauge transformation (CSGT) method. ${ }^{42}$ All NBO, IGAIM and ACID calculations were performed with the M06-2X/def2-TZVP method.

\section{Results and Discussion}

\section{Reaction Pathways}

The choice of systems to investigate associative $\pi$-ligand exchange transition states with the above tools includes those studied both theoretically and experimentally in the gas phase previously. ${ }^{18,24-26}$ These are outlined in Scheme 4 with an array of both identity and non-identity exchange reactions bringing the total to twelve systems.

Variation in the $\mathrm{R}$ group on the chalcogen from $\mathrm{H}$ to $\mathrm{Ph}$ and its impact on the transfer between ethene molecules was first studied, reflecting both Solling et al. earlier theoretical study and those later studied in the gas phase ( $\mathbf{A}$ and $\mathbf{B}$, Scheme 4). ${ }^{18,26}$ This has been continued by varying the alkenes to cyclohexene molecules as previously explored with a phenyl group on the chalcogen $\left(\mathbf{C}\right.$, Scheme 4) ${ }^{26}$ For reactions $\mathbf{B}$ and $\mathbf{C}$, no level of deuteration has been included as was required to be monitored in the gas phase, removing potential deuterium isotope effects and making the systems identity reactions according to IUPAC. ${ }^{43}$ Of the final three non-identity reactions involving transfer of $\mathrm{PhCh}^{+}$from styrene to cyclohexene, the sulphur and selenium systems have been studied previously (D, Scheme 4). ${ }^{24,25}$ Though the telluriranium reaction D3 has not been studied experimentally, it is included here for completeness.

The simplest system was that first studied by Solling, Wild and Radom in which the HS ${ }^{+}$moiety was transferred between two ethenes in an identity exchange reaction (A1, Scheme 4). This has been extended in the present study to include the transfer of $\mathrm{HSe}^{+}$and $\mathrm{HTe}^{+}$between two ethene molecules (A2 and A3 respectively, Scheme 4). The first step in the reaction involves the barrierless formation of the ion-neutral association complex, making the subsequent transfer of the chalcogen moiety the rate determining step. The following ion-neutral dissociation complex for the identity reactions are the same due to symmetry (and were not calculated separately) making these reactions an example of the Brauman double energy well. ${ }^{26,44}$ As a comparison to Radom's calculations, the electronic energy of the association complex and transition state for $\mathrm{HS}^{+}$exchange relative to the reactants was found to be within $2 \mathrm{~kJ} \mathrm{~mol}^{-1}$ of the previous study, reinforcing the accuracy of the M06-2X/def2-TZVP level of theory compared to the high level G2 (ZPE = MP2) theory (A1, Table 1). Of the three systems, the sulphur moiety transfer is predicted not to occur in the gas phase $\left(\Delta E^{\ddagger}=+48.2 \mathrm{~kJ} \mathrm{~mol}^{-1}\right)$ under standard linear ion-trap mass spectrometry conditions described previously, ${ }^{26}$ whilst the tellurium reaction would readily proceed $\left(\Delta E^{\ddagger}=-32.7 \mathrm{~kJ} \mathrm{~mol}^{-1}\right)$. The selenium reaction is more difficult to predict, as although the energy of the transition state is slightly above the energy of the system as defined by the energy of the reactants $\left(\Delta E^{\ddagger}=+6.8 \mathrm{~kJ} \mathrm{~mol}^{-1}\right)$, ion-molecule reactions with calculated barriers up to approximately 9-10 $\mathrm{kJ} \mathrm{mol}^{-1}$ relative to the reactants may still be observed in the gas phase at room temperature, ${ }^{45}$ likely due to a Boltzmann distribution of reactant ion energies and collisions with the helium bath gas. Indeed, the barrier to electrophilic addition of cyclohexene to thiiranium ion $\mathbf{2 7}$ has previously been calculated at $+5 \mathrm{~kJ} \mathrm{~mol}^{-1}$ at the M06-2X/def2-TZVP level of theory, but was observed to proceed with a relatively slow rate coefficient of $3.7 \times 10^{-14} \mathrm{~cm}^{3}$ molecule ${ }^{-1} \mathrm{~s}^{-1}$ in a linear ion trap quadrupole (LTQ) mass spectrometer. ${ }^{25}$ The $\mathrm{S}_{\mathrm{N}} 2$ reaction of ${ }^{37} \mathrm{Cl}^{-}$with $\mathrm{CH}_{3}{ }^{35} \mathrm{Cl}$ has also been shown to proceed with a rate coefficient of $3.5 \times 10^{-14} \mathrm{~cm}^{3}$ molecule ${ }^{-1} \mathrm{~s}^{-1}$ in an ion cyclotron resonance (ICR) spectrometer, ${ }^{46}$ despite a calculated barrier of $+9.8 \mathrm{~kJ} \mathrm{~mol}^{-1}$ relative to the free reactant energies at the $\mathrm{G} 2$ level of theory. ${ }^{45}$ 
The trend of decreasing barriers to $\pi$-ligand exchange moving down the chalcogens has mostly been attributed to the increasing electrophilicity of the chalcogen from sulphur to tellurium. However, the topology of the association complex between the incoming alkene and the iranium ion was also identified as another indicator for whether the reaction would proceed or not. ${ }^{26}$ In the previous study on chalcogen iranium ion identity reactions (see Scheme 3), if the orientation of the $\pi$ orbitals of the alkenes were close to being coplanar in the complex, mirroring the orbital topology in the transition state, then the reaction was predicted to proceed, with both DFT calculations and experimental observations in agreement. However, if the $\pi$ orbital of the incoming alkene donated into a $\sigma^{*}$ Ch-c orbital to form chalcogen bond-like interaction, then the reaction was predicted not to occur and indeed no product formation was observed. Despite the high barrier of $+48.2 \mathrm{~kJ} \mathrm{~mol}^{-1}$ for reaction A1, the calculated orientation of the $\pi$ orbital of ethene relative to the thiiranium ion in complex 31a is not towards a $\sigma^{*}$ s-c orbital. Nevertheless, there is significant deviation from the orientation of the alkene $\pi$ orbitals observed in the transition state 31b (Figure 2). Indeed, looking at the side-on view, the difference in the $\mathrm{C}=\mathrm{C}_{\mathrm{mid}}-\mathrm{Ch}-\mathrm{C}=\mathrm{C}_{\mathrm{mid}}$ angle between the complexes 31a-33a and the transition states 31b-33b reduces going down the group $\left(\Delta \theta_{\mathrm{S}}=7.8^{\circ}>\Delta \theta_{\mathrm{Se}}=2.6^{\circ}>\Delta \theta_{\mathrm{Te}}=0.3^{\circ}\right)$. As shown previously with NBO calculations, this similar topology in the complex reflects the orbitals involved being in an orientation closer to that of the transition state and thus less energy is required for the reaction to proceed.$^{26}$ This trend is also observable in the difference between the Ch-C bond lengths (amongst other structural parameters) in the complex and those in the transition state with the telluriranium ion complex 33a being most like its corresponding transition state 33b (Figure 2).

Comparing to previous calculations by Solling et al. on the topology of the complex relative to that of the transition state, however, reveals that their calculated complex placed the $\pi$ orbitals of the alkenes orthogonal to one another, whilst they were coplanar in the transition state. ${ }^{18}$ Despite the similarity in the calculated energies as mentioned, MP2 has been shown to occasionally incorrectly optimise geometries or miss some minima, such as the benzenium-ethene complex, due to overestimation of electron correlation of double excitations in delocalised systems. ${ }^{47}$ Alternatively, the potential energy surface of complex formation may be rather shallow with several possible minima available, and we have previously suggested that there would be rapid interconversion between the two potential chalcogen bond-like interactions in some of these complexes ${ }^{26}$ Nevertheless, for $\pi$-ligand exchange of chalcogen iranium ions to occur the $\pi$ orbitals of the alkenes must become coplanar, hence the complexes calculated in this study appear to be the more likely ones for the reactions to proceed through.

The energy surfaces of the identity reactions shown in reactions $\mathbf{B}$ and $\mathbf{C}$ have been analysed in detail previously for the corresponding deuterated system, and there is excellent agreement between the two (Table 1). The overall trend of the barrier heights decreasing down the group is observed within each reaction, noting the barrier to $\mathrm{PhSe} \mathrm{e}^{+}$exchange between cyclohexenes in $\mathbf{C 2}$ is lower than the combined reactant energies $\left(\Delta E^{\ddagger}=-8.7 \mathrm{~kJ} \mathrm{~mol}^{-1}\right)$ compared to exchange between ethenes in $\mathbf{B} 2$ as discussed in the previous study. ${ }^{26}$ Comparing the effects of changing the $\mathrm{R}$ substituent from a hydrogen (A) to a phenyl group (B) shows an increase in barrier heights for the latter most likely due to an increase in the steric hindrance to the incoming alkene (Table 1). Further studies are necessary to investigate the effects of the $\mathrm{R}$ group substituent on $\pi$-ligand exchange in the gas phase, and if they correlate with studies mentioned earlier in the condensed phase, ${ }^{7,19}$ but this is beyond the scope of this work.

Figure 3 shows the set of non-identity reactions D1-3 under consideration with the exchange of the chalcogen moiety from styrene to cyclohexene overall exoergic. The reaction of thiiranium ion $\mathbf{2 7}$ with cyclohexene has been shown not to occur in the gas phase as expected based on the modest barrier of $+28.2 \mathrm{~kJ} \mathrm{~mol}^{-1}$ (Black, Figure 3) ${ }^{25}$ The selenium pathway has been shown experimentally to occur with a rate of $6.6 \times 10^{-13} \mathrm{~cm}^{3}$ molecule ${ }^{-1} \mathrm{~s}^{-1},{ }^{24}$ though the relative energy surface mapped out in this study does not agree well with the same one calculated previously at the M06/6-31+G(d) level of theory with 
discrepancies of up to $35 \mathrm{~kJ} \mathrm{~mol}^{-1}$ (Red, Figure 3), noting the latter were reported at $298 \mathrm{~K}$. The surface determined in this study is likely more reliable as we have shown in Table 1 that the M06-2X/def2TZVP level of theory produced results in excellent agreement with the high level G2 (ZPE = MP2) theory, and from previous work RRKM theoretical rates based upon energy surfaces calculated at M06$2 \mathrm{X} / \mathrm{def} 2-\mathrm{TZVP}$ were in good agreement with experimental rates of $\pi$-ligand exchange in the gas phase. ${ }^{26}$

The association complex 28a differs to the one previously calculated in reference 24 as the $\pi$ orbitals of the alkenes are slightly twisted relative to one another rather than adopting the $\pi_{\mathrm{C}=\mathrm{C}}-\sigma^{*} \mathrm{Se-C}$ chalcogen bond-like interaction such as in the thiiranium ion complex 27a. This previous complex has been recalculated at the current level of theory and the energetic difference between complex 28a and 28a' is only $1.1 \mathrm{~kJ} \mathrm{~mol}^{-1}$ with a transition state $\mathbf{2 8 a}$ " connecting the two isomers with a barrier of $1.8 \mathrm{~kJ} \mathrm{~mol}^{-}$ ${ }^{1}$ (Scheme 5). With a margin of error of $\pm 5 \mathrm{~kJ} \mathrm{~mol}^{-1}$ for similar theoretical methods, ${ }^{48}$ the conversion between the two may be considered barrierless and not the rate determining step. Despite the potential for both association complexes $\mathbf{2 8 a}$ and $\mathbf{2 8 a}$ ' to form, the rate determining exchange reaction must proceed via 28a from the IRC calculations, making this complex the only one considered in further analysis.

There are some shifts in the non-identity reaction trends compared to the previous identity reactions detailed above in Figure 3. The change in orientation of the $\pi$ orbitals in the association complex is as expected based on the relative heights of the transition states with 28a and 34a closer to the topology of $\mathbf{2 8 b}$ and 34b, i.e. more coplanar, than in the case of the sulphur association complex 27a and transition state 27b. However, the dissociation complexes are less like the transition states as predicted by the Hammond postulate for exoergic reactions (if the complexes are viewed as reactant and product for the rate determining step). In addition, the trend in energies of the products is reversed compared to the association complexes and transition states with the telluriranium ion $\mathbf{3 4}$ reaction with cyclohexene nearing thermoneutrality. The rates of reactions of seleniranium ions with cycloalkenes of differing ring size have been shown previously to increase with the release of ring strain. ${ }^{24}$ In this reaction, though there is likely some enthalpic force driving formation of the conjugated $\pi$ system in styrene, the ring strain release between styryl derived telluriranium ion $\mathbf{3 4}$ and cyclohexyl derived telluriranium ion 21' is likely smaller than that between the corresponding thiiranium ions $\mathbf{2 7}$ and 19' and seleniranium ions 28 and 20'. The C-Ch-C angle of the iranium ion core may be taken as a marker of ring strain, and indeed the difference between the C-Te-C angles for $\mathbf{3 4}$ and $\mathbf{2 1}$ ' is only $0.1^{\circ}$ compared to $0.8^{\circ}$ and $0.7^{\circ}$ for the corresponding selenium and sulphur systems. This is partially due to the increased donation of the styryl $\pi$-system into the neighbouring $\sigma^{*}{ }_{\mathrm{C} \text {-Te }}$ orbital $\left(E(2)=37 \mathrm{kcal} \mathrm{mol}^{-1}\right.$ from NBO analysis), leading to an increase in the benzylic carbon - tellurium bond length and hence less ring strain in the reactant ion $\mathbf{3 4}$ compared to the others.

Birney et al. have shown that pseudopericyclic transition states of a range of reactions (particularly electrocyclic ring openings and cycloadditions) would have symmetry allowed, near-planar transition states with very low energetic barriers. ${ }^{49-51}$ These characteristics may be investigated in this study for potential pseudocoarctate transition states with the activation energy the difference between the association complex and transition states energies, whilst the planarity may be assessed by the $\mathrm{C}=\mathrm{C}_{\text {mid }}$ - $\mathrm{Ch}-\mathrm{C}=\mathrm{C}_{\mathrm{mid}}$ angle across the dual three-membered ring system. Upon examination, however, there was no clear trend between these two variables $\left(\mathrm{R}^{2}=0.008\right)$ with the selenium systems being the most planar in reactions B2, C2 and D2 (Table 2). Based upon the structure reactivity relationship of the electrocyclic ring openings and cycloaddition reactions, the highest barrier reactions involving the smaller thiiranium systems would be expected to be the least planar and most aromatic with the large telluriranium ion systems exhibiting the opposite features. However, this is not the case and hence this structure reactivity correlation is not an adequate explanation for these systems, perhaps suggesting that 
a shift in the degree of aromaticity may not be a driving force behind the change in reaction barrier height.

Nevertheless, there are some trends between the barrier heights and some other geometric properties of the transition states, namely the related C-Ch bond length and the C-Ch-C angle within each threemembered ring. Indeed, each of these parameters against the barrier heights yield $\mathrm{R}^{2}$ values of 0.825 and 0.808 respectively and removing the outlier of reaction $\mathbf{B 1}$ (points on the far right hand side in Figure 4) increases the $\mathrm{R}^{2}$ to 0.900 (bond length) and 0.893 (angle). The two parameters are not quite interdependent as the discrepancies in the $\mathrm{R}^{2}$ values may be attributed to the slight change in the iranium $\mathrm{C}-\mathrm{C}$ bond length affecting the $\mathrm{C}-\mathrm{Ch}-\mathrm{C}$ angle (see, for example, Figure 2). The trend in ring strain suggests that the small thiiranium ions are less reactive as they are less strained, compared to the larger telluriranium ions, and thus require more energy to transfer the chalcogen moiety to another alkene. The change in bond lengths also implies that less energy is needed to break the longer (weaker) bonds in the larger telluriranium ions leading to lower barriers for $\pi$-ligand exchange. Further examination of the orbital interactions by NBO analysis corroborate these initial findings (vide infra) and provides further insight into whether or not these changes are due to shifts in the degree of aromaticity.

Transition states have a high extent of electron delocalisation, particularly in these types of concerted reactions, meaning one Lewis structure is not an appropriate descriptor. Instead, natural resonance theory (NRT) may be used to examine the different types of Lewis structures that contribute to the overall delocalised structure. For example, analysis of the simplest transition states $\mathbf{3 1 b} \mathbf{b 3 3}$ in reactions A1-3 highlights the increase in positive charge placed on the chalcogen going down the group from sulphur (4.78\%) to selenium (4.87\%) to tellurium (12.34\%) reflecting polarizability trends down the group (Figure 5). The most significant structures place the positive charge on the carbons rather than the chalcogen as shown in Figure 5, but there are minor (about 20-30\%) contributors that assist in distributing the charge further onto the hydrogens of the ethyl moieties (see Tables S1-3 in the Supporting Information for the NRT output).

The introduction of the phenyl group on the chalcogen and cyclohexyl/styryl moieties further distributes the charge leading to even greater delocalisation. However, analysis of all the potential resonance structures is unnecessary as natural charge analysis offers a more efficient and quantitative method to evaluate the degree of positive charge on the chalcogen. As mentioned earlier, the electrophilicity of the chalcogen has been suggested as one of the major drivers in these exchange reactions and this would be expected to reflect the barrier height of the reactions under study. A comparison of these variables produces a correlation with $\mathrm{R}^{2}=0.6318$ (Figure 6), supporting electrophilicity as a significant driver, but not the sole predictive indicator.

The strength of orbital interactions are usually evaluated by the second order perturbation energy, however, initial calculations produced values beyond the second order perturbation limit $(>100 \mathrm{kcal}$ mol $\left.^{-1}\right){ }^{39}$ in particular for the primary $\pi_{\mathrm{C}=\mathrm{C}}-\mathrm{p}^{+} \mathrm{Ch}$ interactions. As mentioned, a single idealised Lewis structure is not an appropriate description for these transition states, which is typical in systems with extensive electron delocalisation. An alternative estimation of stabilisation energies may be instead gained by deleting a Fock matrix element that corresponds to a specific donor-acceptor interaction, whilst leaving other interactions the same, diagonalising the deleted Fock matrix and re-evaluating the total energy of this new density. ${ }^{52}$ The stabilisation (deletion) energy is thus the difference between the total energies before and after matrix-element deletion. This analysis reveals that, generally, the strength of both the primary and secondary interactions changes simultaneously between reactions, and that the reactions with higher barriers have stronger $\pi_{\mathrm{C}=\mathrm{C}}-\mathrm{p}^{+} \mathrm{Ch}$ interactions, suggesting greater electron movement between partially filled and partially vacant orbitals (Table 3). Contrary to initial expectations, the telluriranium ion reactions, which involve a 'softer' tellurium atom with more nucleophilic lone pairs, do not have stronger $\pi_{\mathrm{C}=\mathrm{C}}-\mathrm{p}^{+} \mathrm{Ch}$ or $\mathrm{n}_{\mathrm{Ch}}{ }^{-} \pi^{*} \mathrm{C}=\mathrm{C}$ interactions than the alternative 
thiiranium ion reactions, which involve a 'harder' sulphur atom with more tightly bound lone pairs. This suggests that the orbital overlap must be significantly reduced in the former case leading to less electron delocalisation and hence smaller NBO interactions. This is reflected in the off-diagonal NBO Fock matrix element, $\mathrm{F}_{(\mathrm{i}, \mathrm{j})}$, values (Table 3), which are representative of the extent of orbital overlap and correlate with the trend in bond lengths discussed above (Table 2). For all of the identity reactions (A, B and C), the NBO interactions between the chalcogen and either alkene are very similar (Table 3). However, for the non-identity reaction $\mathbf{D}$, there is a shift in the relative ordering of the interactions with the cyclohexyl moiety donating less $\left(55.3 \mathrm{kcal} \mathrm{mol}^{-1}\right)$ into the $\mathrm{p}^{+} \mathrm{s}$ orbital than the styryl moiety $\left(57.4 \mathrm{kcal} \mathrm{mol}^{-1}\right)$, approximately the same for the $\mathrm{p}^{+} \mathrm{Se}$ orbital, and then significantly more for the former $\left(59.1 \mathrm{kcal} \mathrm{mol}^{-1}\right)$ into the $\mathrm{p}^{+}$Te orbital than the styryl moiety $\left(33.0 \mathrm{kcal} \mathrm{mol}^{-1}\right)$. This trend is also observable in the back-bonding interaction and reflects the exoergicity of the reaction, with the Hammond postulate suggesting the structure of the sulphur transition state $\mathbf{2 7} \mathbf{b}$ will be the most similar to the corresponding association complex $27 \mathbf{a}\left(\pi_{\mathrm{C}=\mathrm{C}}\right.$ styrene $-\mathrm{p}^{+} \mathrm{S}>\pi_{\mathrm{C}=\mathrm{C}}$ cyclohexene $\left.-\mathrm{p}^{+} \mathrm{s}\right)$ as it is the most exoergic of reactions D1-3 (Figure 3).

The nucleus-independent chemical shift (NICS) is an established method that provides a localised examination of magnetic shielding due to electron delocalisation with large negative NICS values often indicating aromaticity. ${ }^{53}$ Despite a study by Wang et al. on the $\pi$-aromaticity of ground state threemembered ring systems suggesting that the dissected NICS(0) $)_{\pi z z}$ value is a suitable indicator (as $\sigma$ electrons dominate the magnetic shielding of the more convenient NICS(1)zz value) ${ }^{54}$ there is the potential of contaminated $\pi$ orbitals from ring substituents of the transition states in this study as the system is not fully planar. ${ }^{55}$ In addition, the ring current is across two dual three-membered rings and NICS has been shown to provide misleading results with polyaromatic hydrocarbons (e.g. anthracene) as it only describes the local ring, not the conjugated system. ${ }^{56}$ Though several studies have provided

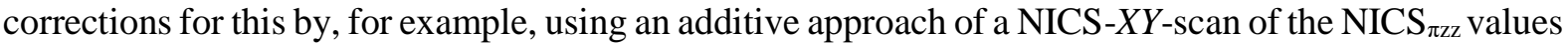
of the subunits of polyacenes, ${ }^{57}$ these methods are not applicable to the $\pi$-ligand exchange transition states as they cannot be broken down into small units with their own ring currents. Thus, other measures of the magnetic properties as indicators of aromaticity in these transition states have been applied.

The anisotropy of the induced current density (ACID) has been used to discriminate between coarctate and pseudocoarctate reactions (as well as pericyclic and pseudopericyclic reactions) by determining the critical isosurface value (CIV). ${ }^{30,58}$ The CIV is the point at which there is a disconnection at a critical point in the ACID scalar field isosurface. If the CIV $<0.02$, then the reaction is considered pseudocoarctate reflecting weak electron delocalisation, whilst if the CIV is $>0.03$ then the reaction is considered to be coarctate reflecting greater electron delocalisation, ${ }^{59}$ generally attributed to aromaticity. Borderline cases occur if the $0.02<\mathrm{CIV}<0.03$, though Young et al have identified a reaction as pseudocoarctate despite a high CIV of $0.044,{ }^{59}$ so these values must be taken into consideration with other criteria as explained. Nevertheless, all reactions studied show CIVs $<0.02$ as shown in Table 4, suggesting that all are pseudocoarctate, which supports the evidence thus far pointing to shifts in aromaticity as a minimal driving factor in these reactions. The split in CIV for reaction D3 is due to the tellurium-cyclohexyl bonds having a slightly higher CIV (0.013) than the tellurium-styryl bonds (0.011) reflecting the different strengths in the NBO interactions. All reaction sets present no discernible trend between reaction barrier and the CIV with reactions $\mathbf{A}$ and $\mathbf{B}$ increasing in CIV down the group, but reactions $\mathbf{C}$ and $\mathbf{D}$ decreasing in CIV down the group. This may be related to the change in alkenes exchanging at the chalcogen, however, all the reactions being pseudocoarctate is the main conclusion from this set of data.

The ACID analysis of transition state $\mathbf{1 5 b}$ from reaction $\mathbf{B 3}$ has been provided in detail as an example of the pseudocoarctate nature of these $\pi$-ligand exchange reactions (Figure 7). The disconnection in the electron delocalisation occurs at a low CIV of 0.015 and occurs simultaneously between the tellurium 
and all four ethene carbons reflecting the concomitant bond breaking and forming at one centre characteristic of a pseudocoarctate reaction. The isosurface alone gives information about the magnitude of the electron delocalisation in the system, but not the direction of the current. Hence, current density vectors were plotted on the isosurface and show a diatropic (clockwise) ring current relative to the applied magnetic field. The ACID analysis supports a borderline non-aromatic/weakly aromatic transition state, characteristic of a pseudocoarctate nature, but not an anti-aromatic nor strongly aromatic system.

The anisotropy of the magnetic susceptibility was used to analyse changes in the magnetic properties along the reaction coordinate. The advantage of examining the anisotropy rather than the total magnetic susceptibility is that it takes the difference between the larger component perpendicular to the ring plane and the smaller components parallel to the ring plane ( $\chi_{\text {anis }}$ is also known as $\Delta \chi$ in the literature) ${ }^{58}$ similar to the $\mathrm{NICS}_{\mathrm{zz}}$ concept, and is hence a more accurate measure of aromaticity. Various studies by Rodriguez-Otero et al. have found that large negative magnetic susceptibility anisotropies accompany aromatic pericyclic transition state species, and that pseudopericyclic transition states (and pseudocoarctate in one study) exhibit either little change, or at most a slight maximum in $\chi_{\text {anis, }}$, along the reaction path relative to the reactants. ${ }^{60-63}$ Reactions A1-3 and $\mathbf{C} 3$ were chosen to investigate whether this held across a variety of reactions with different barrier heights (A1-3), and a barrierless reaction (C3). The non-identity reaction D2 was also considered for analysis, but magnetic susceptibility calculations are global measures of aromaticity and may be influenced by structural moieties that are not of interest (such as the two phenyl rings present in D2), thus giving misleading results. Identity reactions A1-3 show a slight maximum at the transition state (A, Figure 8), supporting the lack of aromaticity in these transition states and hence their pseudocoarctate nature. There is little change in the anisotropy of the magnetic susceptibility along the reaction coordinate for $\mathbf{C 3}$ compared to the complex and this is not surprising given the structural and orbital similarity between the complex and transition state $\left(\mathbf{C 3}\right.$, Figure 8), leading to the near barrierless reaction as mentioned previously. ${ }^{26}$

A first principles approach may be taken to discriminate between coarctate and pseudocoarctate TS by considering Lemal's definition of pseudopericyclic transition states in which "non-bonding and bonding atomic orbitals interchange roles" meaning a "disconnection in the cyclic array of overlapping orbitals" ${ }^{64}$ Figure 9 shows the significant $\pi_{\mathrm{C}=\mathrm{C}}-\mathrm{p}^{+} \mathrm{Ch}$ and $\mathrm{n}_{\mathrm{Ch}}-\pi^{*}{ }_{\mathrm{C}=\mathrm{C}}$ NBO interactions in TS 31b and, as hinted at earlier in Figure 1, the vacant $\mathrm{p}^{+}$orbital and the lone pair on the sulphur atom are orthogonal to one another leading to a disconnection in the orbital array at the central chalcogen. The first part of the above definition is more discerning as the chalcogen lone pair that interacts with the $\pi^{*}$ orbitals of the alkenes at the transition state is liberated from one of the $\sigma_{\mathrm{Ch}-\mathrm{C}}$ orbitals of the initial iranium ion. NBO analysis along the reaction coordinate supports this as it shows that, though there is one lone pair available on the chalcogen from reactant to product (it is anti to the S-H bond), the lone pair interacting at the transition state only appears when the $\sigma_{\mathrm{Ch}-\mathrm{C}}$ bonds are broken (evident from detection of the natural hybrid orbital's (NHO) polar and azimuthal angles of the lone pair). The points along the pathway at which this interchange from bonding to non-bonding orbitals occurs for reactions A1-3, C3 and D2 are collated in Tables S4-8 with the bond breaking occurring earlier for those reactions with lower barriers (such as A3). Thus, it is likely that every associative $\pi$-ligand exchange reaction of a chalcogen iranium ion is pseudocoarctate regardless of the nature of the central moiety or the alkenes it is being exchanged between.

\section{Conclusion}

The nature of the mechanism of $\pi$-ligand exchange reactions of chalcogen iranium ions has been explored comprehensively by DFT calculations based on previous computational and experimental work. Exploration of these reactions revealed not only the electrophilicity of the chalcogen as a reactivity factor, but also the overall strain in the iranium ions both in the reactants and products. The 
initial association complex's similarity to the transition state was also observed to be a continual indicator of reactivity with lower barriers predicted, if not barrierless altogether, the greater the similarity. The NBO analysis supported earlier suggestions of two key interactions at the transition state involving two primary $\pi_{\mathrm{C}=\mathrm{C}}-\mathrm{p}^{+} \mathrm{Ch}$ and one secondary $\mathrm{n}_{\mathrm{Ch}}-\pi^{*}{ }_{\mathrm{C}=\mathrm{C}}$ leading to a Hückel number of delocalised $\pi$ electrons. Based on these interactions and the previous experimental work, the $\pi$-ligand exchange reactions must be considered diagnostic of the iranium ion structure (rather than isomeric onium ions). The same conclusion has been made by Heck et al. for chloriranium and bromiranium ions (referred to as cyclic ethylenehalonium ions) for the transfer of a halogen moiety between alkenes. ${ }^{65}$ The nature of these reactions was suggested to be pseudocoarctate (non-aromatic/weakly aromatic) rather than coarctate (aromatic) by analysis of the magnetic properties both at the transition state (ACID) and along the reaction coordinate $\left(\chi_{\text {anis }}\right)$. Further NBO analysis along the reaction coordinate supported Lemal's definition of pseudopericyclic transition states, which may be applied to pseudocoarctate transition states as well, with an interchange from bonding $\left(\sigma_{\mathrm{Ch}-\mathrm{C}}\right)$ to non-bonding $\left(\mathrm{n}_{\mathrm{Ch}}\right)$ orbitals during the reaction leading to disconnections in the orbital array. This work has also highlighted the fact that there are limited tools available to explore the magnetic properties of dual three-membered ring systems and may prompt further development in the field for understanding other transition states involving structural moieties outside of six- and five-membered rings.

\author{
Author Information \\ Corresponding Authors \\ *(S.C.B.) E-mail: brydons@student.unimelb.edu.au. \\ *(J.M.W.) E-mail: whitejm@unimelb.edu.au. \\ ORCID
}

Samuel C. Brydon: 0000-0002-8939-0249

Gabriel da Silva: 0000-0003-4284-4474

Jonathan M. White: 0000-0002-0707-6257

\title{
Conflicts of Interest
}

There are no conflicts to declare.

\section{Acknowledgments}

We thank the Australian Government for a Research Training Program (RTP) scholarship to S.B. The DFT calculations were performed on the Spartan High Performance Computing (HPC) System hosted by the Research Platform Services at the University of Melbourne. ${ }^{66}$ Thanks to Fynn Roehricht from the Herges research group for help in setting up the ACID program. ACID calculations were conducted on the Argali HPC Service provided by the Melbourne School of Engineering hosted at the University of Melbourne.

\section{Notes and References}

1. $\quad$ Mueller, W. H. Angew Chem Int Ed Eng 1969, 8(7), 482-492.

2. Smit, V. A.; Zefirov, N. S.; Bodrikov, I. V.; Krimer, M. Z. Acc Chem Res 1979, 12(8), 282288.

3. Modena, G.; Pasquato, L.; Lucchini, V. Phosphorus, Sulfur, Silicon Relat Elem 1994, 95(1-4), 265-282.

4. Rayner, C. M. In Organosulfur Chemistry; Page, P., Ed.; Academic Press, 1995, p 89-131.

5. Danielle, M. B.; Thomas, W. Curr Org Chem 2006, 10(15), 1893-1903.

6. Wirth, T. Angew Chem Int Ed 2000, 39(21), 3740-3749. 
7. Denmark, S. E.; Kalyani, D.; Collins, W. R. J Am Chem Soc 2010, 132(44), 15752-15765.

8. Hartmann, E.; Denmark, S. E. Helv Chim Acta 2017, $100(9)$, e1700158.

9. Denmark, S. E.; Hartmann, E.; Kornfilt, D. J. P.; Wang, H. Nat Chem 2014, 6(12), 1056-

1064 .

10. Poleschner, H.; Seppelt, K. Eur J Chem 2018, 24(64), 17155-17161.

11. Bock, J.; Daniliuc, C. G.; Bergander, K.; Mück-Lichtenfeld, C.; Hennecke, U. Org Biomol Chem 2019, 17(12), 3181-3185.

12. Denmark, S. E.; Collins, W. R.; Cullen, M. D. J Am Chem Soc 2009, 131(10), 3490-3492.

13. Smit, W. A.; Krimer, M. Z.; Vorob'eva, E. A. Tetrahedron Lett 1975, 16(29), 2451-2454.

14. Capon, B. Q Rev Chem Soc 1964, 18(1), 45-111.

15. Schmid, G. H.; Strukelj, M.; Dalipi, S. Can J Chem 1987, 65(8), 1945-1950.

16. Denmark, S. E.; Vogler, T. Eur J Chem 2009, 15(43), 11737-11745.

17. Denmark, S. E.; Kornfilt, D. J. P. J Org Chem 2017, 82(6), 3192-3222.

18. Sølling, T. I.; Wild, S. B.; Radom, L. Eur J Chem 1999, 5(2), 509-514.

19. Toshimitsu, A.; Nakano, K.; Mukai, T.; Tamao, K. J Am Chem Soc 1996, 118(11), 2756-

2757.

20. Toshimitsu, A.; Ito, M.; Uemura, S. J Chem Soc, Chem Commun 1989(9), 530-531.

21. Toshimitsu, A. Phosphorus, Sulfur, Silicon Relat Elem 2005, 180(3-4), 935-937.

22. Maji, B. Adv Synth Catal 2019, 361(15), 3453-3489.

23. Ascheberg, C.; Bock, J.; Buß, F.; Mück-Lichtenfeld, C.; Daniliuc, C. G.; Bergander, K.; Dielmann, F.; Hennecke, U. Eur J Chem 2017, 23(48), 11578-11586.

24. Lim, S. F.; Harris, B. L.; Khairallah, G. N.; Bieske, E. J.; Maître, P.; da Silva, G.; Adamson, B. D.; Scholz, M. S.; Coughlan, N. J. A.; O’Hair, R. A. J.; Rathjen, M.; Stares, D.; White, J. M. J Org Chem 2017, 82(12), 6289-6297.

25. Brydon, S. C.; Lim, S. F.; Khairallah, G. N.; Maître, P.; Loire, E.; da Silva, G.; O’Hair, R. A. J.; White, J. M. J Org Chem 2019, 84(16), 10076-10087.

26. Brydon, S. C.; Ren, Z.; da Silva, G.; Lim, S. F.; Khairallah, G. N.; Rathjen, M. J.; White, J.

M.; O'Hair, R. A. J. J Phys Chem A 2019, 123(38), 8200-8207.

27. Ortgies, S.; Breder, A. ACS Catal 2017, 7(9), 5828-5840.

28. Herges, R. J Chem Inf Model 1994, 34(1), 91-102.

29. Herges, R. Angew Chem Int Ed Eng 1994, 33(3), 255-276.

30. Herges, R. J Org Chem 2015, 80(23), 11869-11876.

31. Frisch, M.J.; Trucks, G.W.; Schlegel, H.B.; Scuseria, G. E.; Robb, M. A.; Cheeseman, J. R.;

Scalmani, G.; Barone, V.; Petersson, G. A.; Nakatsuji, H.; et al. Gaussian Revision B.01; Gaussian, Inc., Wallingford CT, 2016.

32. Zhao, Y.; Truhlar, D. G. Theor Chem Acc 2008, 120(1), 215-241.

33. Weigend, F.; Ahlrichs, R. Phys Chem Chem Phys 2005, 7(18), 3297-3305.

34. Mardirossian, N.; Head-Gordon, M. Mol Phys 2017, 115(19), 2315-2372.

35. Zhao, Y.; Truhlar, D. G. J Org Chem 2007, 72(1), 295-298.

36. Dau, P. D.; Armentrout, P. B.; Michelini, M. C.; Gibson, J. K. Phys Chem Chem Phys 2016, 18(10), 7334-7340.

37. Glendening, E. D.; Badenhoop, J, K.; Reed, A. E.; Carpenter, J. E.; Bohmann, J. A.; Morales, C. M.; Karafiloglou, P; Landis, C. R.; Weinhold, F. NBO 7.0. Theoretical Chemistry Institute, University of Wisconsin, Madison, 2018.

38. Hanwell, M. D.; Curtis, D. E.; Lonie, D. C.; Vandermeersch, T.; Zurek, E.; Hutchison, G. R. J Cheminformatics 2012, 4(1), 17.

39. Weinhold, F.; Landis, C. R.; Glendening, E. D. Int Rev Phys Chem 2016, 35(3), 399-440.

40. Keith, T. A.; Bader, R. F. W. Chem Phys Lett 1992, 194(1), 1-8.

41. Geuenich, D.; Hess, K.; Köhler, F.; Herges, R. Chem Rev 2005, 105(10), 3758-3772.

42. Keith, T. A.; Bader, R. F. W. Chem Phys Lett 1993, 210(1), 223-231.

43. IUPAC Gold Book, https://goldbook.iupac.org/terms/view/I02940, (accessed January, 2020).

44. Brauman, J. I. J Mass Spectrom 1995, 30(12), 1649-1651. 
45. Glukhovtsev, M. N.; Pross, b. A.; Radom, L. J Am Chem Soc 1995, 117(7), 2024-2032.

46. Wladkowski, B. D.; Brauman, J. I. J Phys Chem 1993, 97(50), 13158-13164.

47. Schwabe, T.; Grimme, S. J Phys Chem A 2009, 113(13), 3005-3008.

48. Zheng, J.; Zhao, Y.; Truhlar, D. G. J Chem Theory Comput 2009, 5(4), 808-821.

49. Birney, D. M. J Am Chem Soc 2000, 122(44), 10917-10925.

50. Birney, D. M. J Org Chem 1996, 61(1), 243-251.

51. Zhou, C.; Birney, D. M. J Am Chem Soc 2002, 124(18), 5231-5241.

52. Carpenter, J. E.; Weinhold, F. J Mol Struc Theochem 1988, 169, 41-62.

53. Chen, Z.; Wannere, C. S.; Corminboeuf, C.; Puchta, R.; Schleyer, P. v. R. Chem Rev 2005, 105(10), 3842-3888.

54. Wang, H.-J.; Schleyer, P. v. R.; Wu, J. I.; Wang, Y.; Wang, H.-J. Int J Quantum Chem 2011, 111(5), 1031-1038.

55. Gershoni-Poranne, R.; Stanger, A. Chem Soc Rev 2015, 44(18), 6597-6615.

56. Bultinck, P. Faraday Discuss 2007, 135(0), 347-365.

57. Gershoni-Poranne, R. Eur J Chem 2018, 24(16), 4165-4172.

58. Herges, R. In The Chemical Bond; Shaik, G. F. a. S., Ed., 2014, p 383-420.

59. Young, B. S.; Herges, R.; Haley, M. M. Chem Commun 2012, 48(76), 9441-9455.

60. Cabaleiro-Lago, E. M.; Rodríguez-Otero, J.; García-López, R. M.; Peña-Gallego, A.;

Hermida-Ramón, J. M. Eur J Chem 2005, 11(20), 5966-5974.

61. Rodríguez-Otero, J.; Cabaleiro-Lago, E. M. Angew Chem Int Ed 2002, 41(7), 1147-1150.

62. Peña-Gallego, A.; Rodríguez-Otero, J.; Cabaleiro-Lago, E. M. Eur J Org Chem 2005, 2005(15), 3228-3232.

63. Rodríguez-Otero, J.; Cabaleiro-Lago, E. M. Eur J Chem 2003, 9(8), 1837-1843.

64. Ross, J. A.; Seiders, R. P.; Lemal, D. M. J Am Chem Soc 1976, 98(14), 4325-4327.

65. Heck, A. J. R.; de Koning, L. J.; Nibbering, N. M. M. Org Mass Spectrom 1993, 28(3), 235-

244.

66. Lafayette, L.; Sauter, G.; Vu, L.; Meade, B. Spartan Performance and Flexibility: An HPC-Cloud Chimera. Presented at the OpenStack Summit, Barcelona, October 27, 2016.

Table 1. Electronic energies of the complexes and transition states of identity reactions A1-3, B1-3 and C1-3 relative to the free reactants calculated at M06-2X/def2-TZVP compared to previous studies (in $\left.\mathrm{kJ} \mathrm{mol}^{-1}\right)$.

This Study

\begin{tabular}{|c|c|c|c|c|c|}
\hline \multirow[b]{2}{*}{ Reaction } & & \\
\hline & Complex & $\begin{array}{c}\text { Transition } \\
\text { State }\end{array}$ & $\begin{array}{c}\text { Association } \\
\text { Complex }\end{array}$ & $\begin{array}{l}\text { Transition } \\
\text { State }\end{array}$ & $\begin{array}{c}\text { Dissociation } \\
\text { Complex }\end{array}$ \\
\hline A1* & -24.1 & +48.2 & -25.6 & +46.6 & -25.6 \\
\hline A2 & -27.1 & +6.8 & & & \\
\hline A3 & -38.5 & -32.7 & & & \\
\hline B1 ${ }^{\#}$ & -17.2 & +79.8 & -17.2 & +80.6 & -15.3 \\
\hline B2 $2^{\#}$ & -21.0 & +29.2 & -21.0 & +30.0 & -19.1 \\
\hline $\mathbf{B 3}^{\#}$ & -30.0 & -17.3 & -30.0 & -16.8 & -28.7 \\
\hline $\mathrm{C1}^{\#}$ & -28.2 & +34.0 & -28.3 & +33.3 & -29.8 \\
\hline $\mathrm{C2}^{\#}$ & -32.0 & -8.7 & -32.1 & -9.4 & -33.4 \\
\hline $\mathbf{C 3}^{\#}$ & -48.9 & -48.9 & -49.4 & -49.6 & -49.8 \\
\hline
\end{tabular}

*Compared to those in reference 18 calculated at G2 $(\mathrm{ZPE}=\mathrm{MP} 2)$ on optimised MP2(full)/6-31G(d) geometries. ${ }^{\#}$ Compared to those partially deuterated systems in reference 26 calculated at M06-2X/def2TZVP on geometries optimised at the same level. Blank spaces are for those with no prior study. 
Table 2. Barrier heights relative to association complexes ( $\left.\Delta E^{\ddagger} \mathrm{RDS}\right)$ and selected geometric parameters for the transition states of reactions A-D.
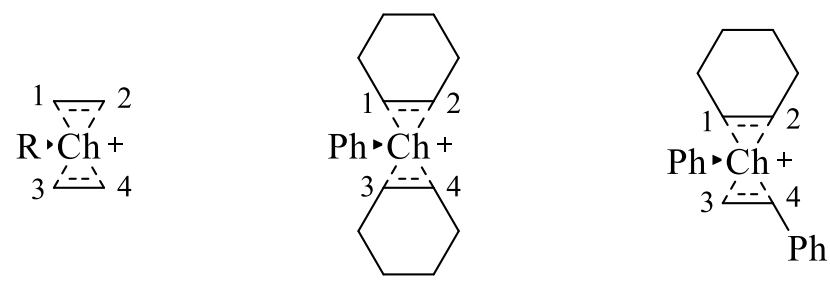

\begin{tabular}{|c|c|c|c|c|c|c|c|c|}
\hline Reaction & $\Delta E^{\ddagger} \mathrm{RDS} *$ & $\mathbf{M I D}^{\# \wedge}$ & $\begin{array}{c}\mathrm{C}_{1}-\mathrm{Ch}- \\
\mathrm{C}_{2}{ }^{\wedge}\end{array}$ & $\begin{array}{c}\mathrm{C}_{3}-\mathrm{Ch}- \\
\mathrm{C}_{4}{ }^{\wedge}\end{array}$ & $\mathbf{C}_{1}-\mathrm{Ch}^{\&}$ & $\mathrm{C}_{2}-\mathbf{C h}^{\&}$ & $\mathrm{C}_{3}-\mathrm{Ch}^{\&}$ & $\mathbf{C}_{4}-\mathbf{C h}^{\&}$ \\
\hline A1 & +72.3 & 9.7 & 34.0 & 34.0 & 2.327 & 2.327 & 2.327 & 2.327 \\
\hline A2 & +33.9 & 11.1 & 32.4 & 32.4 & 2.436 & 2.436 & 2.436 & 2.436 \\
\hline A3 & +5.8 & 13.9 & 30.2 & 30.2 & 2.603 & 2.603 & 2.603 & 2.603 \\
\hline B1 & +97.0 & 3.9 & 33.1 & 33.1 & 2.381 & 2.381 & 2.381 & 2.381 \\
\hline B2 & +50.2 & 1.0 & 31.9 & 31.9 & 2.470 & 2.470 & 2.470 & 2.470 \\
\hline B3 & +12.7 & 6.6 & 29.9 & 29.9 & 2.628 & 2.628 & 2.628 & 2.628 \\
\hline C1 & +62.2 & 5.6 & 33.0 & 33.0 & 2.410 & 2.395 & 2.396 & 2.410 \\
\hline C2 & +23.3 & 0.8 & 31.8 & 31.8 & 2.504 & 2.485 & 2.484 & 2.504 \\
\hline C3 & +0.1 & 5.6 & 29.7 & 29.8 & 2.664 & 2.646 & 2.643 & 2.661 \\
\hline D1 & +60.6 & 8.8 & 33.0 & 32.7 & 2.389 & 2.425 & 2.283 & 2.519 \\
\hline D2 & +23.7 & 4.2 & 31.8 & 31.5 & 2.500 & 2.490 & 2.399 & 2.598 \\
\hline D3 & +2.2 & 4.6 & 30.9 & 28.6 & 2.579 & 2.573 & 2.656 & 2.807 \\
\hline
\end{tabular}

$* \Delta E_{\mathrm{RDS}}^{\ddagger}=E^{\ddagger}-E_{\text {association complex }}$ in $\mathrm{kJ} \mathrm{mol}^{-1 \text { \# }}$ Taken as the absolute difference between the angle of the midpoint of one $\mathrm{C}=\mathrm{C}$ bond to the chalcogen to the other $\mathrm{C}=\mathrm{C}$ bond, and $180^{\circ} .{ }^{\wedge}$ in degrees $\left({ }^{\circ}\right) .{ }^{\&}$ in angstrom $(\AA)$.

Table 3. Selected natural bond orbital interactions determined by deletions analysis (in $\mathrm{kcal} \mathrm{mol}^{-1}$ ).

\begin{tabular}{|c|c|c|c|c|c|c|c|c|}
\hline \multirow[t]{2}{*}{ Reaction } & \multicolumn{2}{|c|}{$\pi_{\mathrm{C} 1=\mathrm{C} 2}-\mathbf{p}^{+} \mathrm{Ch}$} & \multicolumn{2}{|c|}{$\pi_{\mathrm{C} 3=\mathrm{C} 4}-\mathbf{p}^{+} \mathrm{Ch}$} & \multicolumn{2}{|c|}{$\mathbf{n}_{\mathrm{Ch}-} \pi^{*} \mathrm{Cl}=\mathrm{C} 2$} & \multicolumn{2}{|c|}{$n_{\mathrm{Ch}}-\pi^{*} \mathrm{C} 3=\mathrm{C} 4$} \\
\hline & $\mathrm{E}_{\mathrm{DEL}}$ & $F_{(i, j)}$ & $\mathrm{E}_{\mathrm{DEL}}$ & $F_{(i, j)}$ & $\mathrm{E}_{\mathrm{DEL}}$ & $F_{(i, j)}$ & $\mathrm{E}_{\mathrm{DEL}}$ & $F_{(i, j)}$ \\
\hline A1 & 73.3 & 0.170 & 73.3 & 0.170 & 19.8 & 0.091 & 19.8 & 0.091 \\
\hline A2 & 66.9 & 0.161 & 66.9 & 0.161 & 19.0 & 0.087 & 19.0 & 0.087 \\
\hline A3 & 53.8 & 0.146 & 53.9 & 0.146 & 16.7 & 0.078 & 16.7 & 0.078 \\
\hline B1 & 61.8 & 0.157 & 61.8 & 0.157 & 15.8 & 0.081 & 15.8 & 0.081 \\
\hline B2 & 59.3 & 0.153 & 59.3 & 0.153 & 16.7 & 0.081 & 16.7 & 0.081 \\
\hline B3 & 48.9 & 0.140 & 48.9 & 0.140 & 15.4 & 0.075 & 15.4 & 0.075 \\
\hline C1 & 57.9 & 0.151 & 57.8 & 0.150 & 12.8 & 0.076 & 12.8 & 0.076 \\
\hline C2 & 55.5 & 0.146 & 55.4 & 0.146 & 13.3 & 0.076 & 13.2 & 0.076 \\
\hline C3 & 44.6 & 0.132 & 45.0 & 0.133 & 11.8 & 0.069 & 12.0 & 0.069 \\
\hline D1 & 55.2 & 0.149 & 57.4 & 0.154 & 12.4 & 0.075 & 12.8 & 0.075 \\
\hline D2 & 54.6 & 0.147 & 54.1 & 0.146 & 13.0 & 0.074 & 13.0 & 0.075 \\
\hline D3 & 59.1 & 0.150 & 33.0 & 0.117 & 16.4 & 0.079 & 8.6 & 0.059 \\
\hline
\end{tabular}

Table 4. Critical isosurface values (CIV) determined by anisotropy of the induced current density analysis for reactions A-D

\begin{tabular}{|c|c|c|c|}
\hline REACTION & CIV & REACTION & CIV \\
\hline A1 & 0.011 & C1 & 0.014 \\
\hline A2 & 0.011 & $\mathrm{C} 2$ & 0.012 \\
\hline A3 & 0.013 & $\mathrm{C3}$ & 0.011 \\
\hline B1 & 0.012 & D1 & 0.016 \\
\hline B2 & 0.013 & D2 & 0.013 \\
\hline B3 & 0.015 & D3 & $0.013 / 0.011$ \\
\hline
\end{tabular}




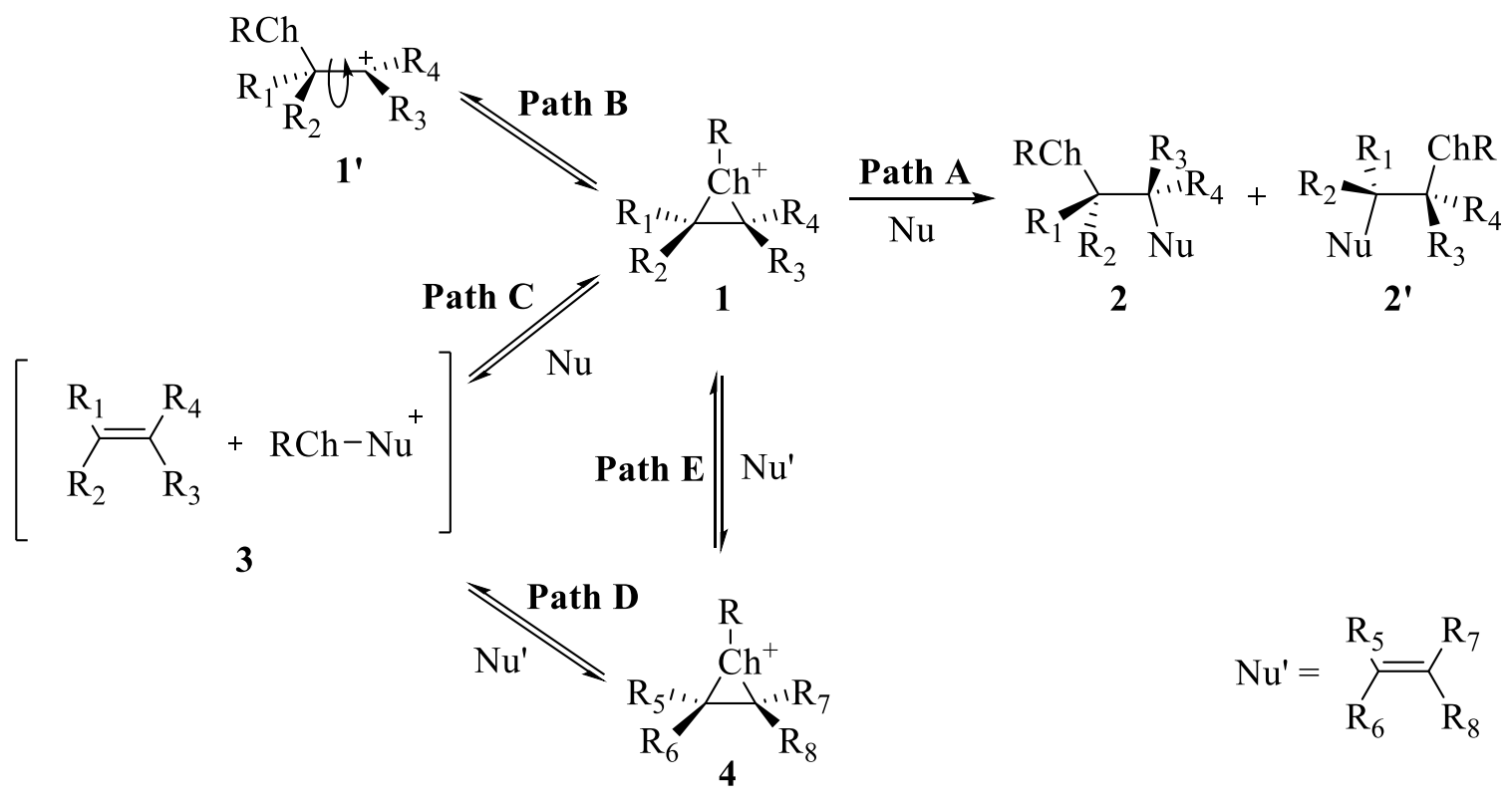

Scheme 1. Reaction and racemisation pathways of chalcogen $(\mathrm{Ch}=\mathrm{S}$, Se or Te) iranium ion 1 with nucleophiles (adapted from references 16 and 24)

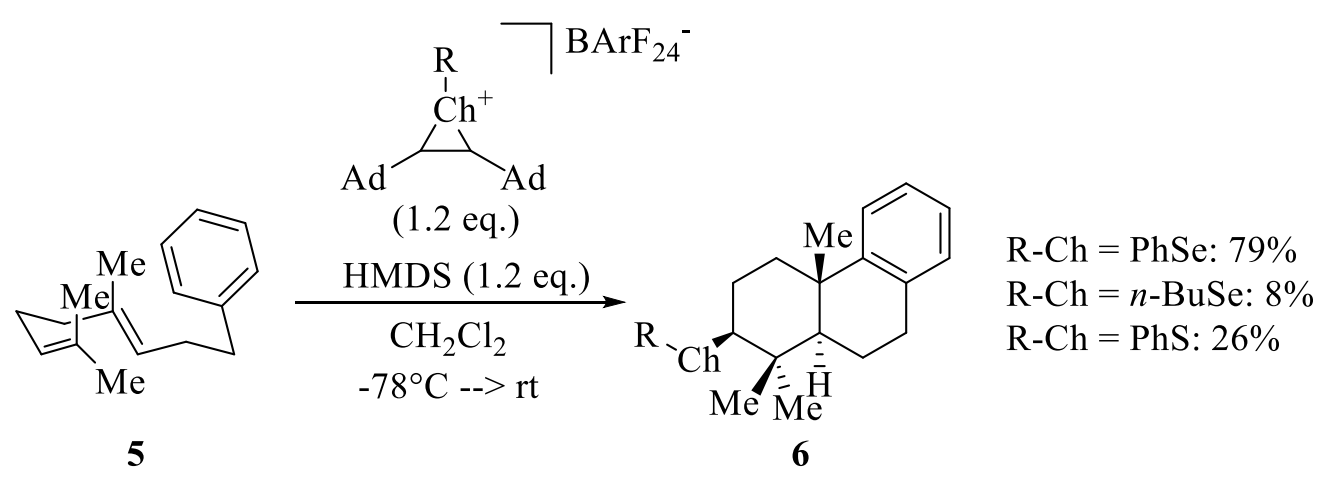

Scheme 2. Polyene type cyclisation of $\mathbf{5}$ to give tricyclic $\mathbf{6}$ induced by chalcogen iranium ions in the presence of non-coordinating counter ion tetrakis(3,5-bis(trifluoromethyl)phenyl)borate, $\mathrm{BArF}_{24}{ }^{-}$ (adapted from reference 11). 


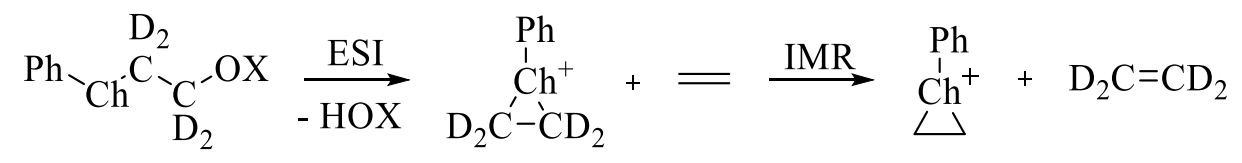

7: $\mathrm{Ch}=\mathrm{S}, \mathrm{X}=\mathrm{H}$

8: $\mathrm{Ch}=\mathrm{Se}, \mathrm{X}=\mathrm{H}$

9: $\mathrm{Ch}=\mathrm{Te}, \mathrm{X}=\mathrm{Ac}$
10: $\mathrm{Ch}=\mathrm{S}(\mathrm{m} / \mathrm{z} 141)$

11: $\mathrm{Ch}=\mathrm{Se}(m / z$ 189)

12: $\mathrm{Ch}=\mathrm{Te}(m / z 239)$
13: $\mathrm{Ch}=\mathrm{S}$ (Not observed)

14: $\mathrm{Ch}=\mathrm{Se}$ (Not observed)

15: $\mathrm{Ch}=\mathrm{Te}(\mathrm{m} / \mathrm{z} 235)$<smiles>CC(=O)O[C@H]1CCCC[C@H]1[CH]c1ccccc1</smiles><smiles>c1ccc([In]2C3CCCCC32)cc1</smiles><smiles>[R]C1([18O])CC=CCC1</smiles>

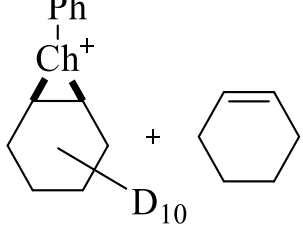

16: $\mathrm{Ch}=\mathrm{S}$

19: $\mathrm{Ch}=\mathrm{S}(m / z$ 191)

17: $\mathrm{Ch}=\mathrm{Se}$

20: $\mathrm{Ch}=\mathrm{Se}(m / z 239)$

18: $\mathrm{Ch}=\mathrm{Te}$

21: $\mathrm{Ch}=\mathrm{Te}(\mathrm{m} / \mathrm{z} 289)$

22: S (Not observed)

23: $\mathrm{Se}(\mathrm{m} / z$ 249)

24: $\mathrm{Te}(\mathrm{m} / z$ 299)

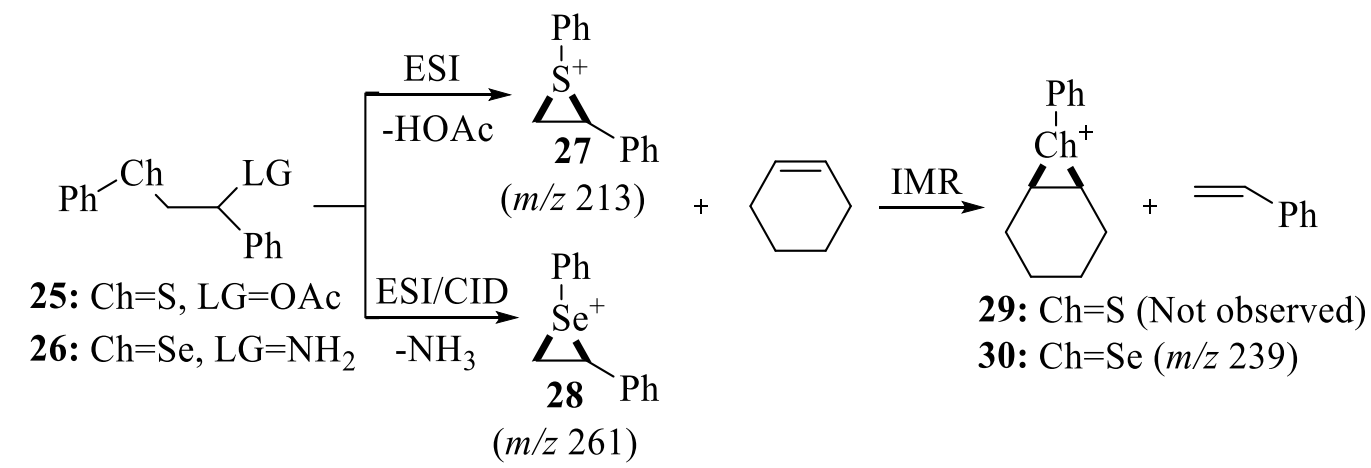

Scheme 3. Experimental $\pi$-ligand exchange reactions of chalcogen iranium ions 10-12, 19-21 and 2728 in the gas phase performed in a linear ion-trap quadrupole (LTQ) mass spectrometer (adapted from references 24-26). $L G=$ leaving group.

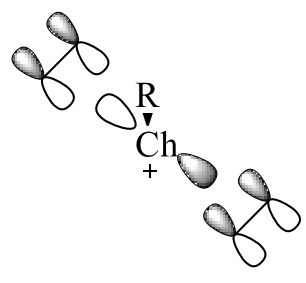

$\pi_{\mathrm{C}=\mathrm{C}}-\mathrm{p}^{+} \mathrm{Ch}$

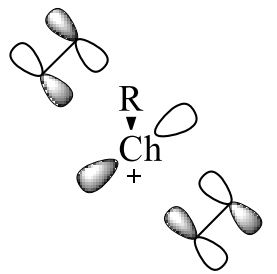

$\mathrm{n}_{\mathrm{Ch}}-\pi^{*} \mathrm{C}=\mathrm{C}$

Figure 1. Significant orbital interactions in the transition states of $\pi$-ligand exchange of chalcogen iranium ions (adapted from reference 18). 

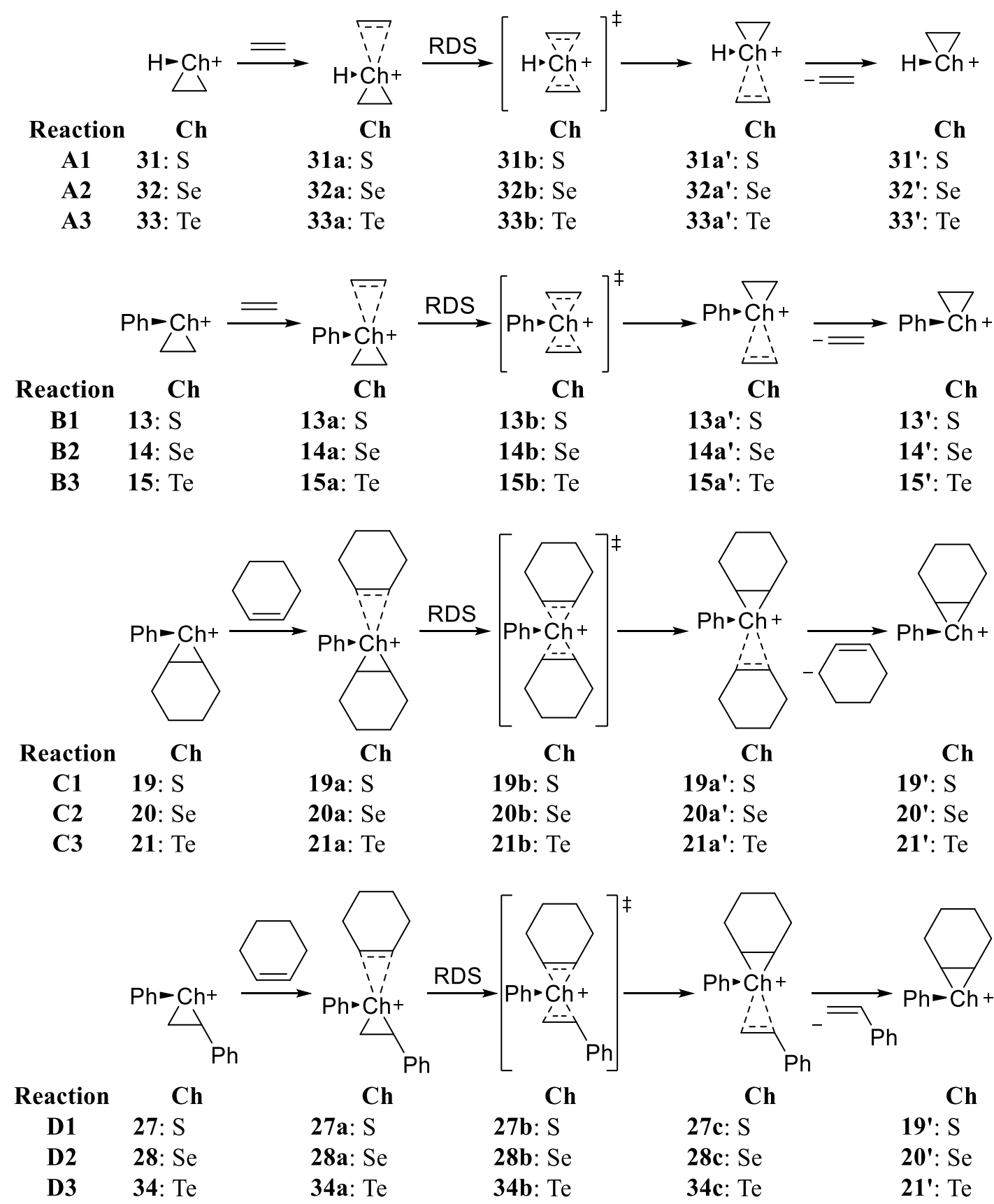

Scheme 4. $\pi$-Ligand exchange identity $(\mathbf{A}, \mathbf{B}$ and $\mathbf{C})$ and non-identity (D) reactions of chalcogen iranium ions with the rate determining step (RDS) indicated (based on references 24-26). 


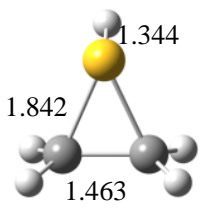

31

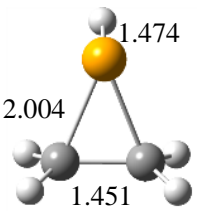

32

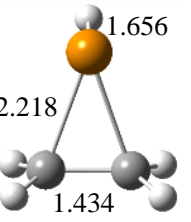

33

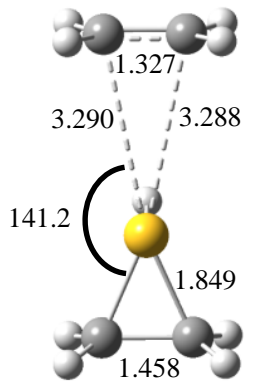

31a (front)

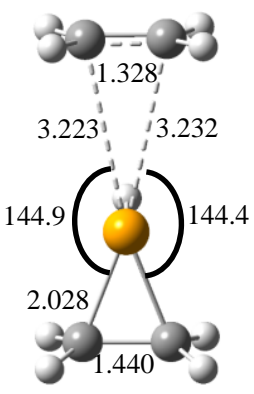

32a (front)

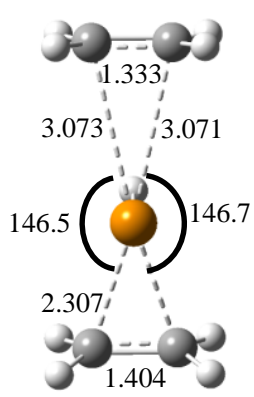

33a (front)

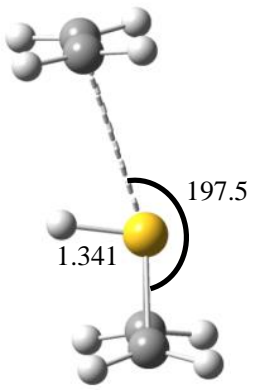

31a (side)

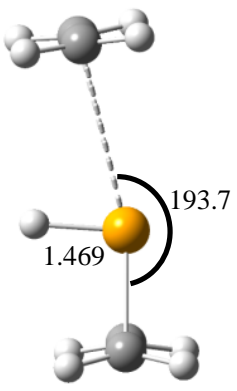

32a (side)

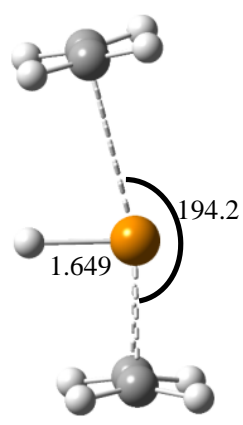

33a (side)
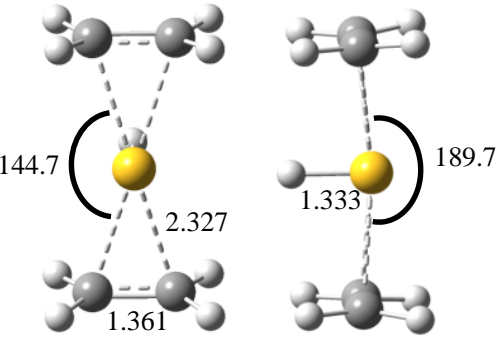

31b (front)

31b (side)
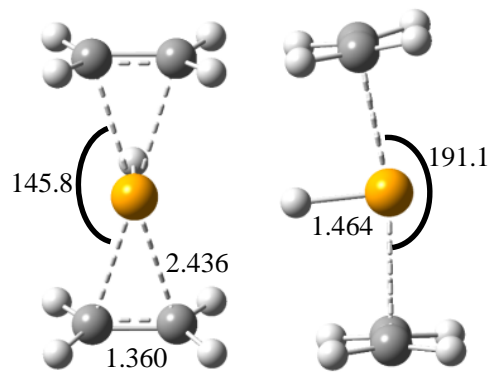

32b (front)

32b (side)
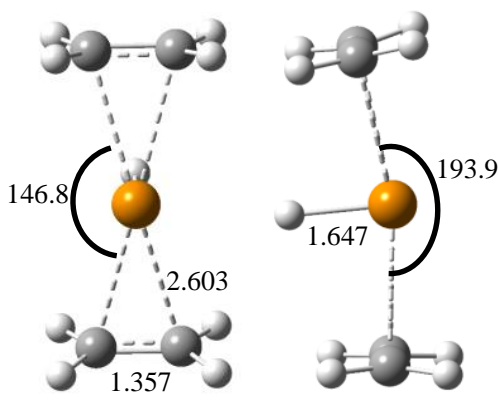

33b (front)

33b (side)

Figure 2. Calculated structures for key species in reactions $\mathbf{A 1}$ (top), $\mathbf{A 2}$ (middle) and A3 (bottom). Bond lengths in angstrom $(\AA)$, angles in degrees $\left(^{\circ}\right)$. Due to symmetry, not all key bond lengths and angles are given if the same to the third or first decimal place respectively. 


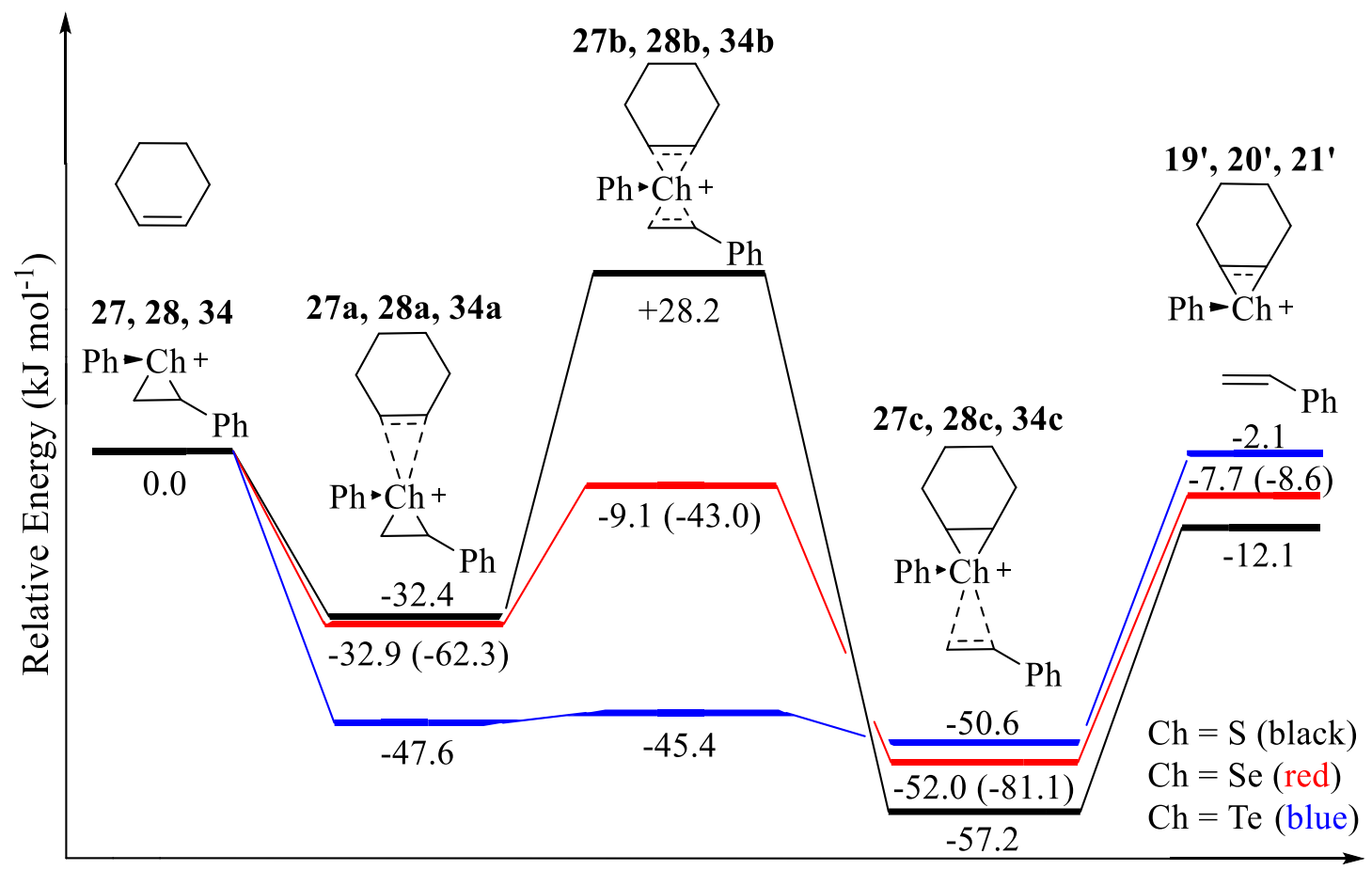

Reaction Coordinate
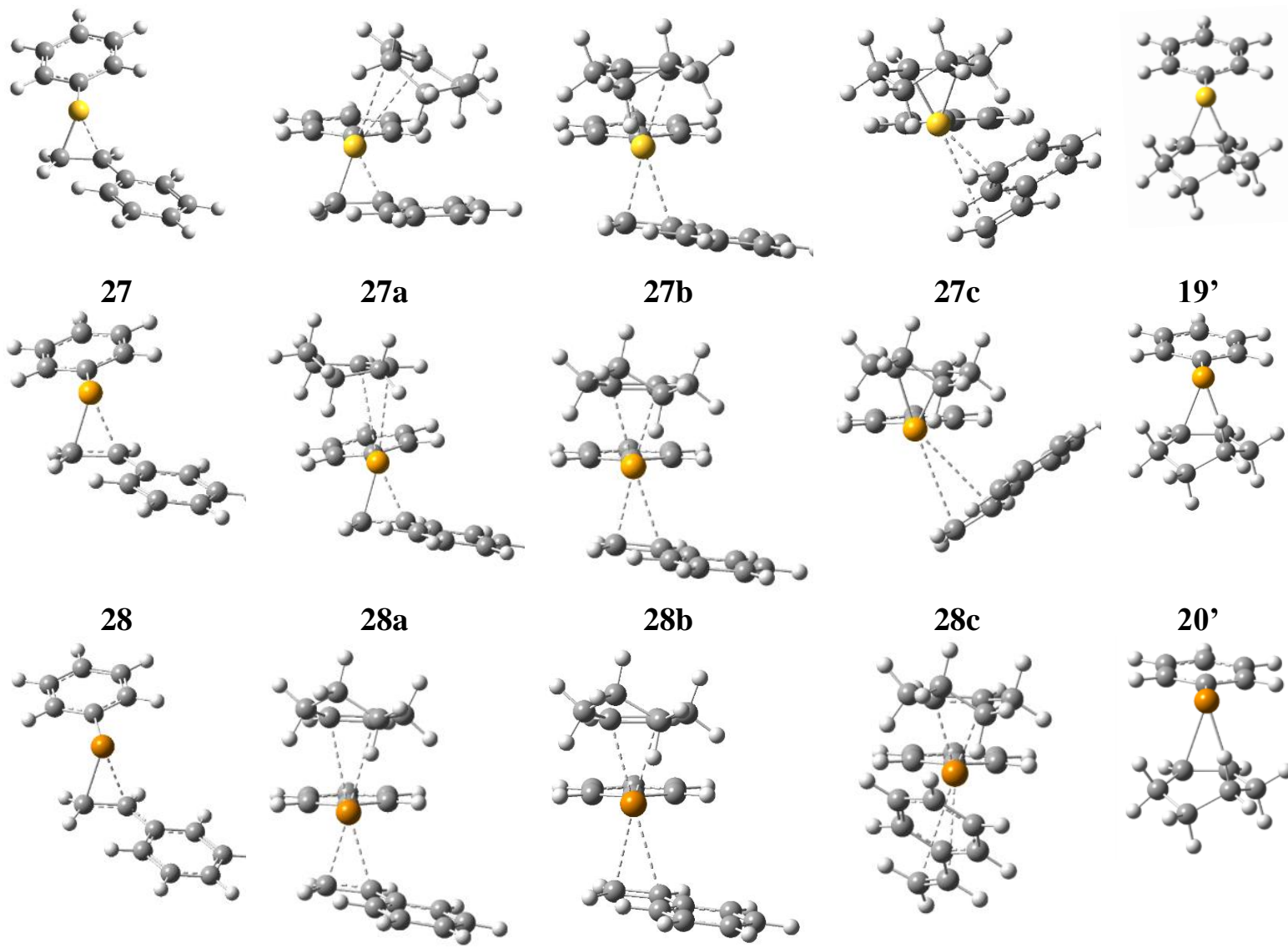

34

34a
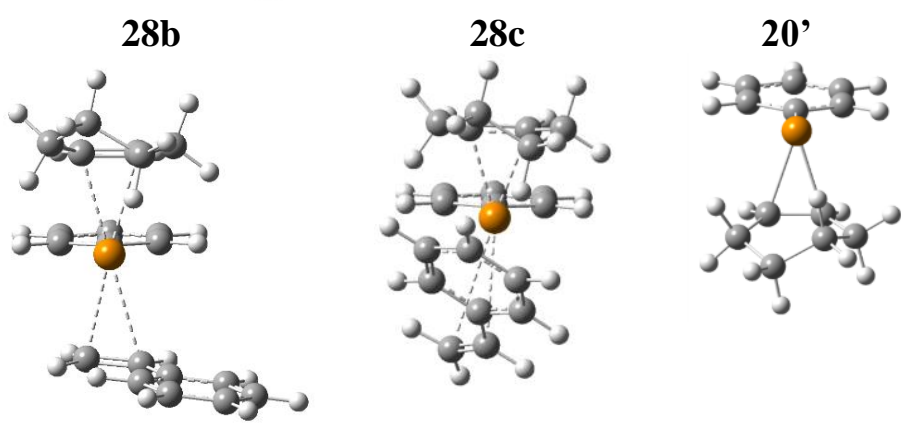

34b

$34 c$

21' 
Figure 3. Relative energy diagram of D1-3 $\pi$-ligand exchange reactions for chalcogen iranium ions 27 (adapted from reference 25), 28 and 34 with cyclohexene to afford products 19'-21' $(\mathrm{Ch}=\mathrm{S}$ - black; $\mathrm{Se}$ - red; Te - blue). Energies given as $\Delta E$ in $\mathrm{kJ} \mathrm{mol}^{-1}$ at M06-2X/def2-TZVP relative to the free reactants. Energies in brackets correspond to previous study of $\mathrm{Ch}=\mathrm{Se}$ calculated at M06/6-31+G(d), given as $\Delta E$ at $298 \mathrm{~K}$ in kJ mol$^{-1}{ }^{24}$

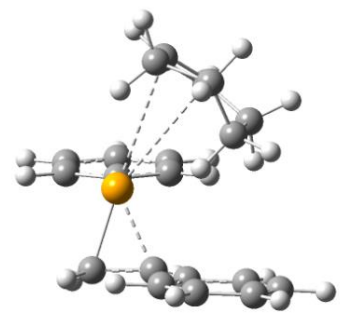

28a'

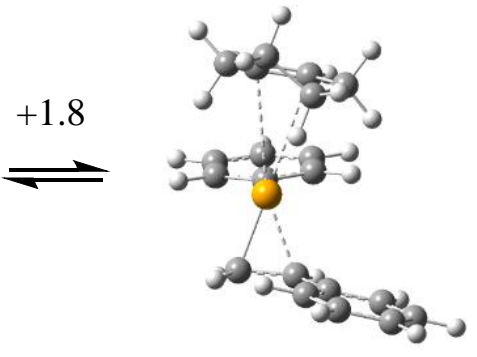

28a",

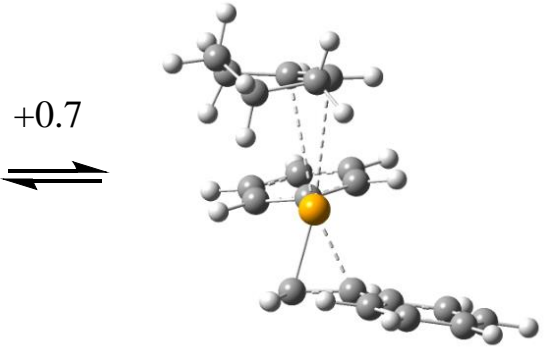

28a

Scheme 5. Isomerisation of $\mathbf{2 8 a}$ ' to $\mathbf{2 8 a}$ via transition state $\mathbf{2 8 a}{ }^{\prime}$. Energies given as $\Delta E$ in $\mathrm{kJ} \mathrm{mol}^{-1}$ at M06-2X/def2-TZVP relative to $\mathbf{2 8 a}$ '.

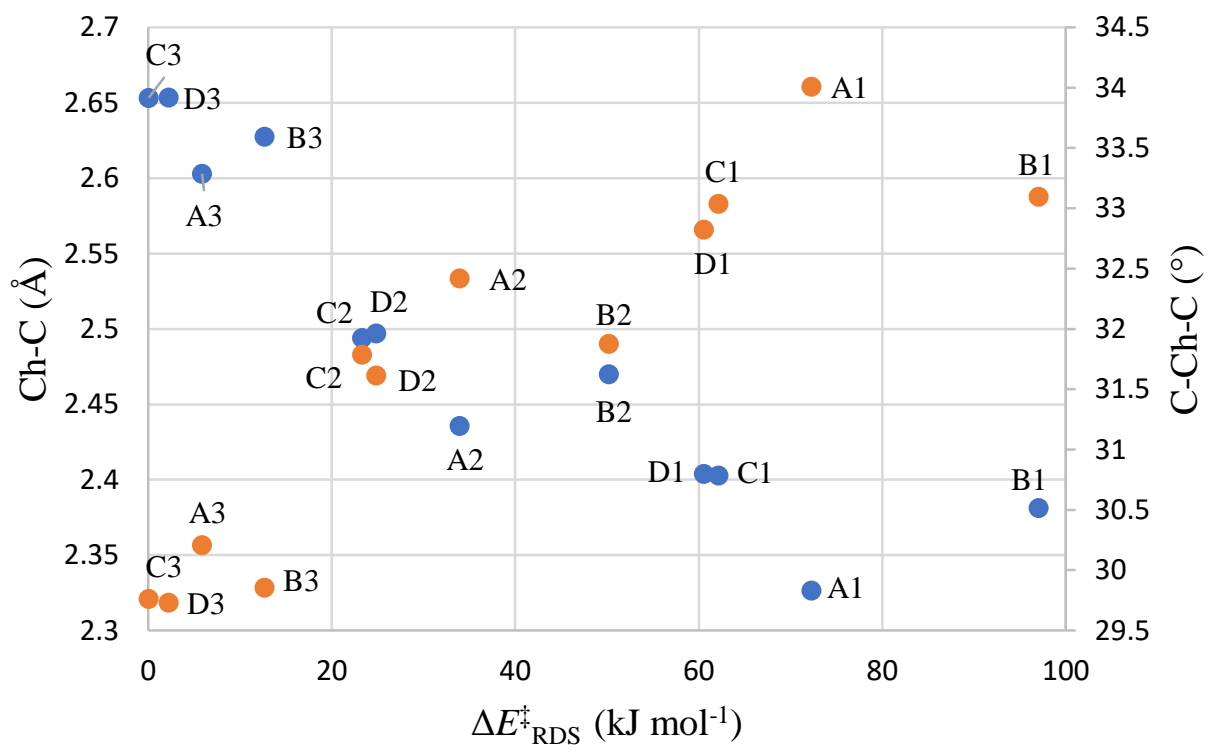

Figure 4. Plot of the average Ch-C bond length in $\AA$ (blue dots, $\mathrm{R}^{2}=0.825$ ) and the average C-Ch-C angle in ${ }^{\circ}$ (orange dots, $\mathrm{R}^{2}=0.808$ ) for transition states in reactions $\mathbf{A}-\mathbf{D}$ against barrier height relative to association complex $\left(\mathrm{kJ} \mathrm{mol}^{-1}\right)$.
$\mathrm{H}-{ }^{+}$
$\overline{\mathrm{H}-\mathrm{S}^{+}}$
${ }_{\mathrm{H}-\mathrm{Se}}^{+}$
$\overline{\overline{\mathrm{H}-\mathrm{Se}^{+}}}$
${ }_{\mathrm{H}-\mathrm{Te}}^{+}$
$\overline{\overline{\mathrm{H}-\mathrm{Te}^{+}}}$
$4 \times \overline{\overline{6.4}} 4 \%$
$4.7 \overline{\overline{8 \%}}$
$4 \times \overline{\overline{16.65}} \%$
$4 \overline{\overline{87 \%}}$
$4 \times 15.97 \%$
$12.34 \%$

Figure 5. Selected Lewis structures from natural resonance theory analysis of transition states $\mathbf{3 1 b}$ 33b 


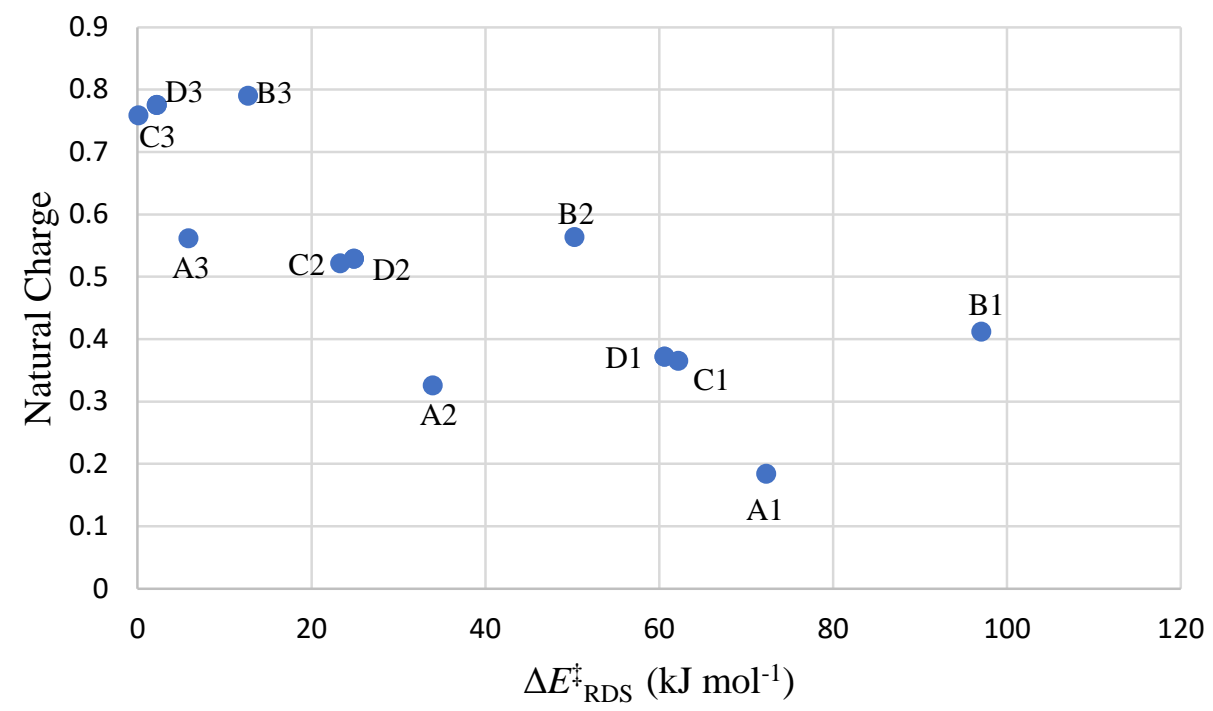

Figure 6. Plot of natural charge on the chalcogen for all transition states against barrier height relative to the association complex $\left(\mathrm{kJ} \mathrm{mol}^{-1}\right)$ with $\mathrm{R}^{2}=0.6318$. 


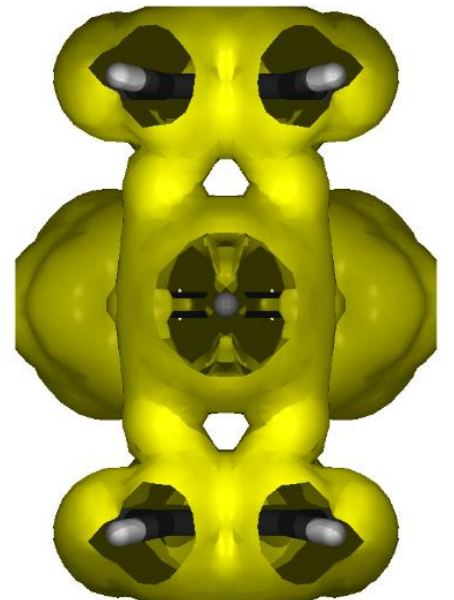

Isosurface $=0.01 \mathrm{au}$

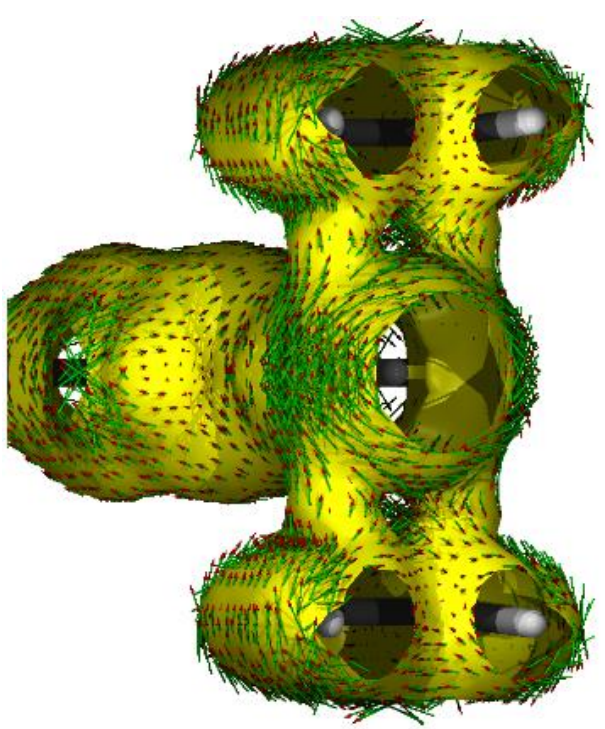

Isosurface $=0.01 \mathrm{au}$
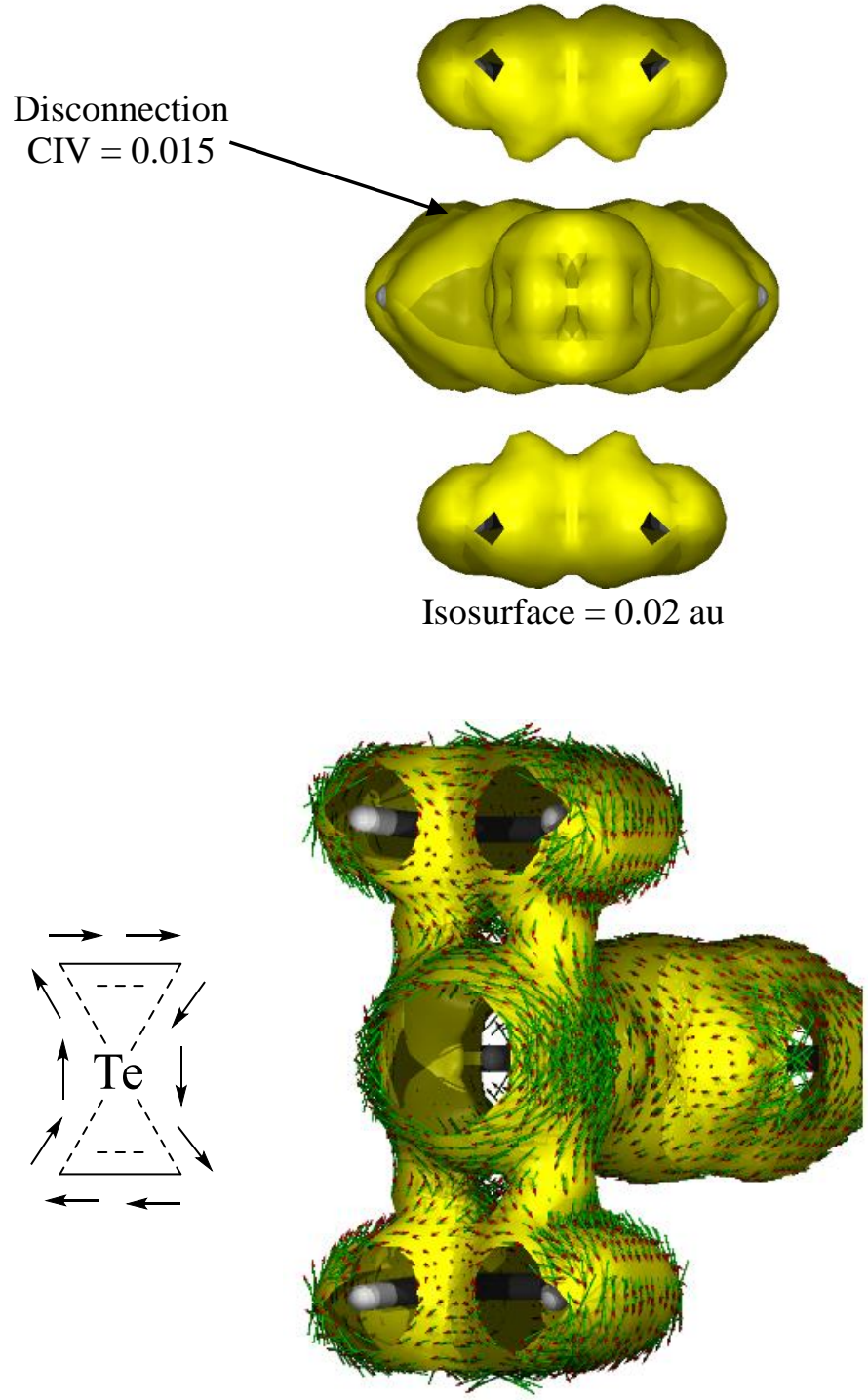

Isosurface $=0.01 \mathrm{au}$

Figure 7. ACID plots at variable isosurface values of transition state $\mathbf{1 5 b}$ from reaction $\mathbf{B 3}$ involving the transfer of the $\mathrm{PhTe}^{+}$moiety between ethenes with all four of the bonds breaking/forming having a CIV value of 0.015 as indicated in the top structures. The current density vectors have been plotted on the two bottom structures to show the direction of the ring current (the right hand side has been rotated $180^{\circ}$ around the $\mathrm{C}=\mathrm{C}_{\mathrm{mid}}-\mathrm{Ch}-\mathrm{C}=\mathrm{C}_{\mathrm{mid}}$ axis) with the diagram in the centre (the phenyl group points into the page and is omitted for clarity) representing the direction of electron flow as black arrows. The direction of the magnetic field lies along the $\mathrm{Ph}-\mathrm{Te}$ axis pointing out of the page. 


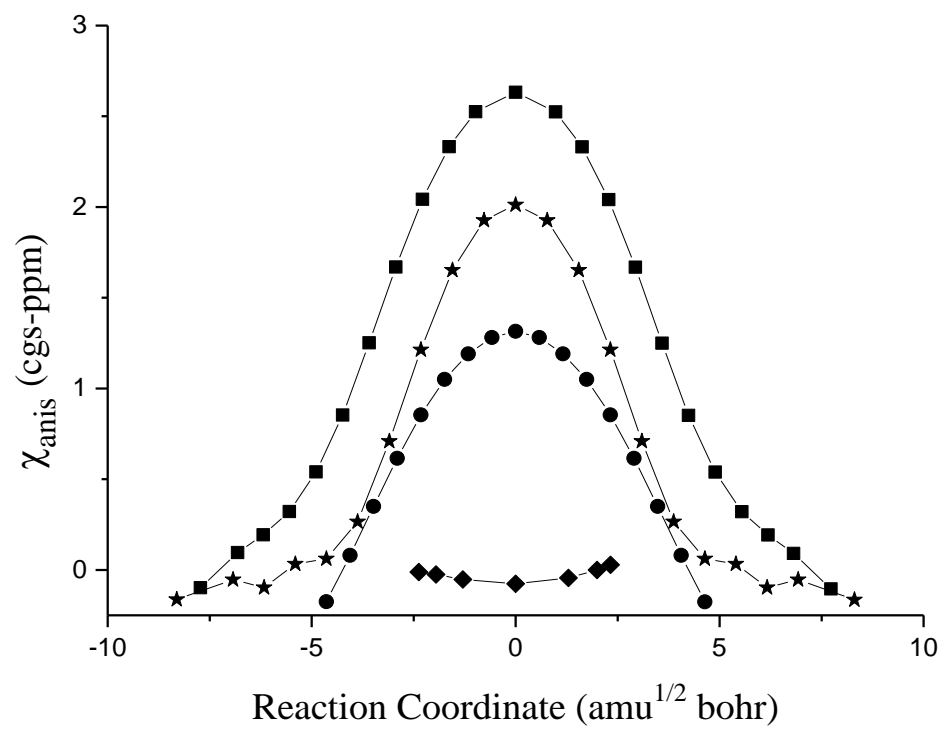

Figure 8. Change in the anisotropy of the magnetic susceptibility, $\chi_{\text {anis, }}$ (cgs-ppm) along the reaction coordinate $\left(\mathrm{amu}^{1 / 2} \mathrm{bohr}\right)$ of identity reactions $\mathbf{A 1}(\star), \mathbf{A 2}(\mathbf{\bullet}), \mathbf{A 3}(\bullet)$ and $\mathbf{C 3}(\bullet)$ relative to respective association complexes (raw data is collated in Tables S4-7 in the Supporting information).

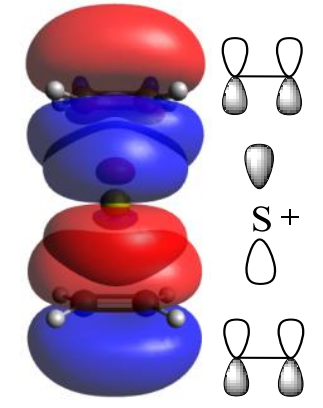

$2 \times \pi_{\mathrm{C}=\mathrm{C}}-\mathrm{p}^{+} \mathrm{Ch}$

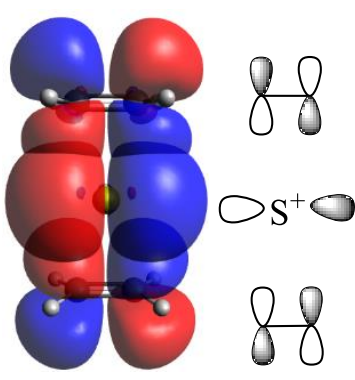

$\mathrm{n}_{\mathrm{Ch}}-\pi^{*} \mathrm{C=C}$

Figure 9. Significant natural bond orbital interactions in the sulphur transition state $\mathbf{3 1 b}$ visualised at an isosurface value of 0.02 au. Hydrogens have been excluded in the schematic orbitals for clarity. 


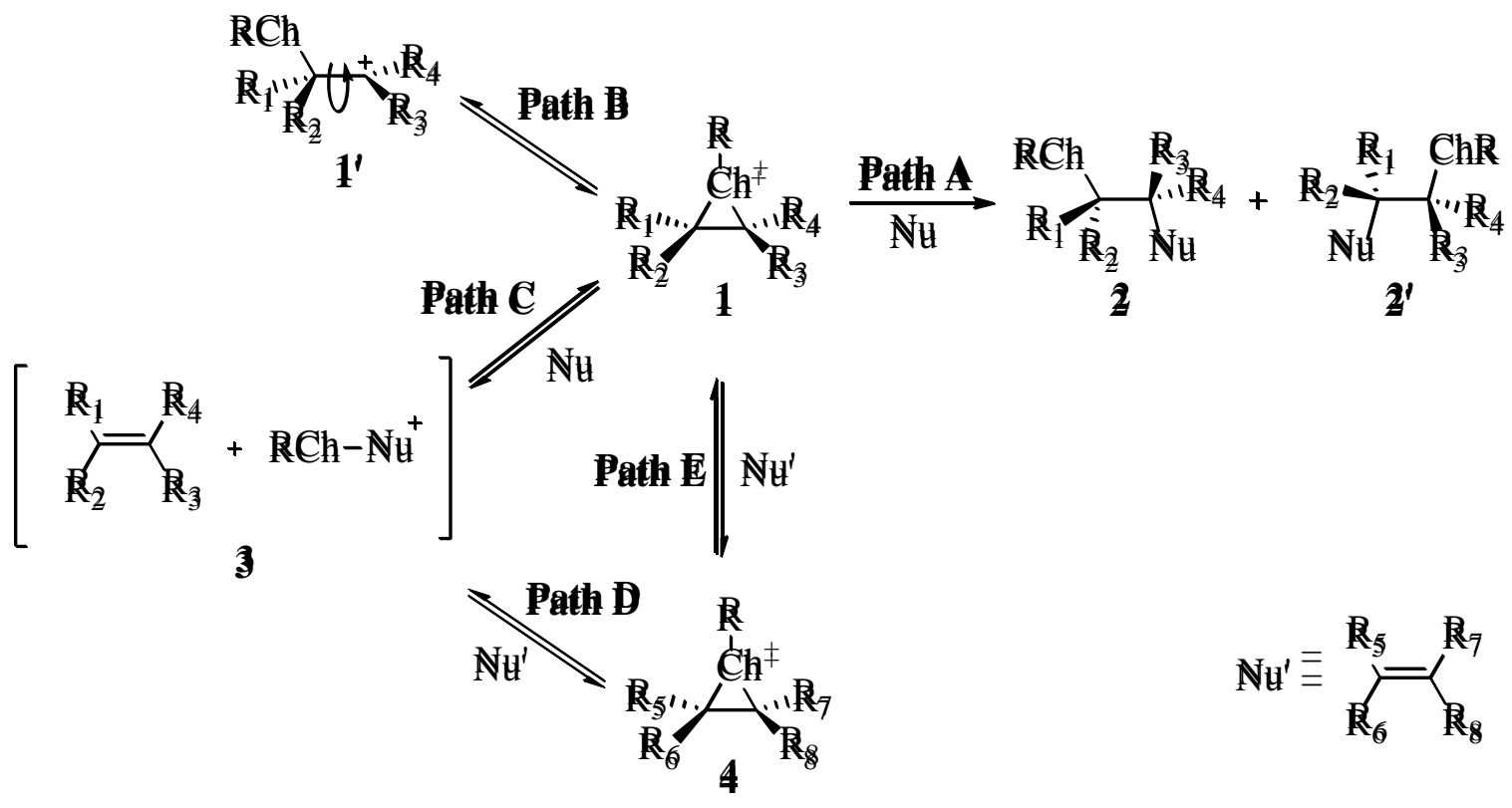

Scheme 1. Reaction and racemisation pathways of chalcogen $(\mathrm{Ch}=\mathrm{S}$, Se or Te) iranium ion $\mathbf{1}$ with nucleophiles (adapted from references 16 and 24)

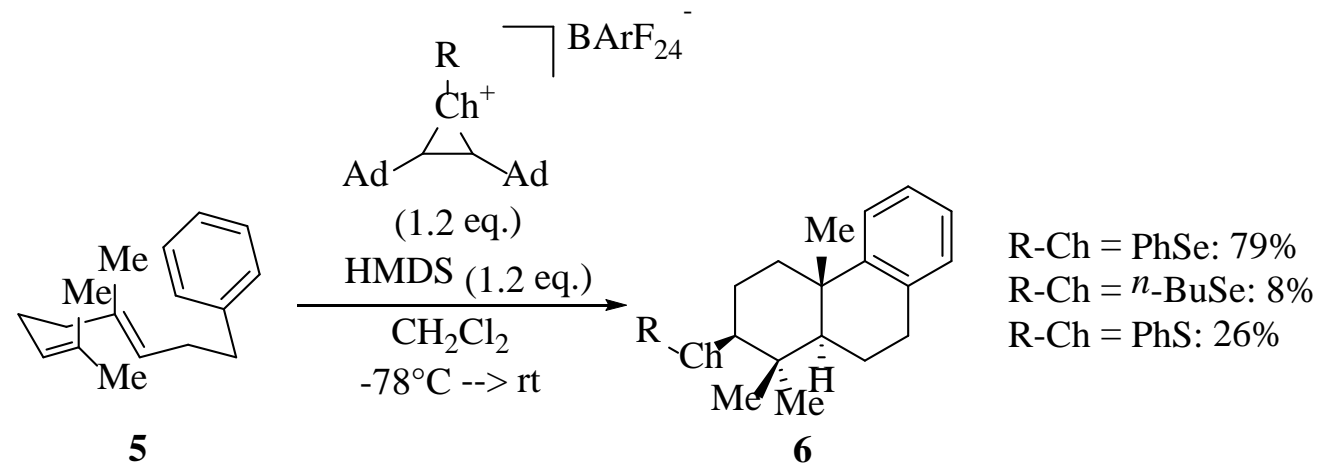

Scheme 2. Polyene type cyclisation of 5 to give tricyclic $\mathbf{6}$ induced by chalcogen iranium ions in the presence of non-coordinating counter ion tetrakis(3,5-bis(trifluoromethyl)phenyl)borate, $\mathrm{BArF}_{24}{ }^{-}$ (adapted from reference 11). 


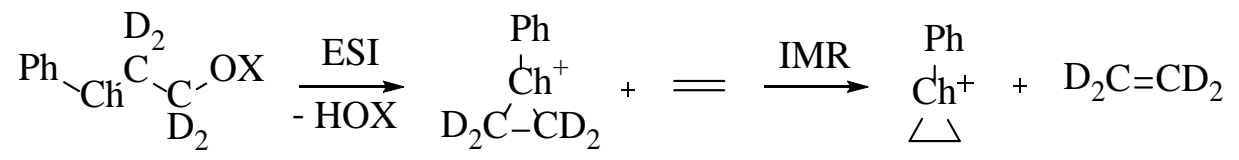

7: $C h=S, X=H$
8: $C h=S e, X=H$
9: $C h=T e, X=A c$

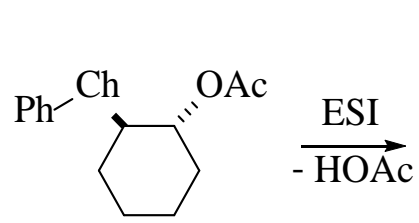

10: $\mathrm{Ch}=\mathrm{S}(\mathrm{m} / \mathrm{z} 141)$

11: $\mathrm{Ch}=\mathrm{Se}(\mathrm{m} / \mathrm{z}$ 189)

12: $\mathrm{Ch}=\mathrm{Te}(\mathrm{m} / \mathrm{z}$ 239)
13: $\mathrm{Ch}=\mathrm{S}$ (Not observed)

14: $\mathrm{Ch}=\mathrm{Se}$ (Not observed)

15: $\mathrm{Ch}=\mathrm{Te}(\mathrm{m} / \mathrm{z} 235)$

$\mathrm{Ph}$<smiles>[GeH2]</smiles><smiles>[R10]C1([2H])CC=CCC1</smiles><smiles>[Pb]C12CCCC(CC1)C2</smiles>

22: S (Not observed)

23: Se $(m / z 249)$

24: Te $(m / z$ 299)

17: $\mathrm{Ch}=\mathrm{Se}$

19: $\mathrm{Ch}=\mathrm{S}(\mathrm{m} / \mathrm{z}$ 191)

18: $\mathrm{Ch}=\mathrm{Te}$

$=$ Se $(m / z 239)$

21: $\mathrm{Ch}=\mathrm{Te}(\mathrm{m} / \mathrm{z} 289)$

$\mathrm{Ph}$

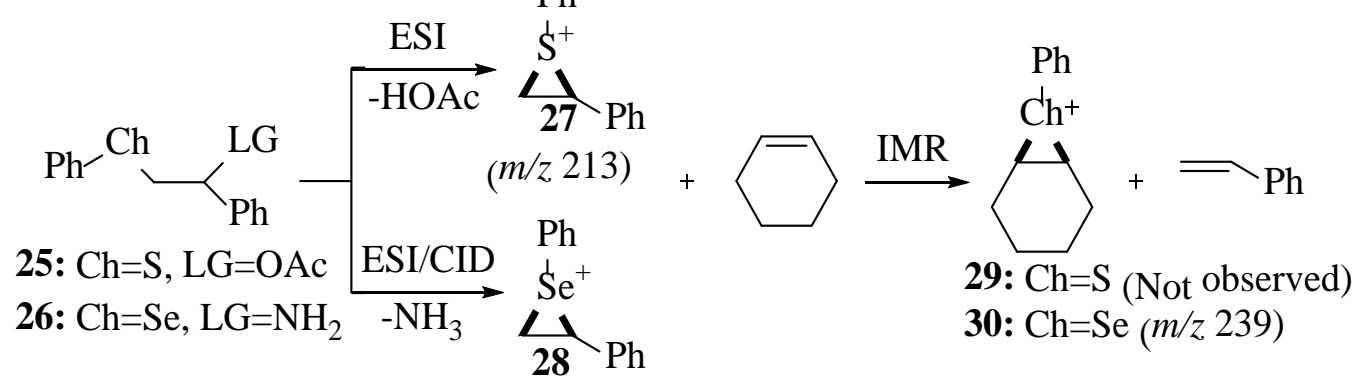

$(\mathrm{m} / \mathrm{z} 261)$

Scheme 3. Experimental $\pi$-ligand exchange reactions of chalcogen iranium ions 10-12, 19-21 and 2728 in the gas phase performed in a linear ion-trap quadrupole (LTQ) mass spectrometer (adapted from references 24-26). LG = leaving group.

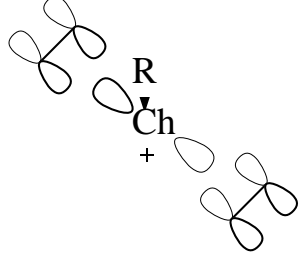

$$
\pi_{\mathrm{C}=\mathrm{C}}-\mathrm{p}^{+} \mathrm{Ch}
$$

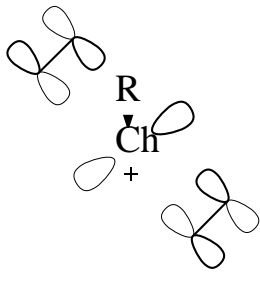

$\mathrm{n}_{\mathrm{Ch}}-\pi^{*} \mathrm{C}=\mathrm{C}$

Figure 1. Significant orbital interactions in the transition states of $\pi$-ligand exchange of chalcogen iranium ions (adapted from reference 18). 

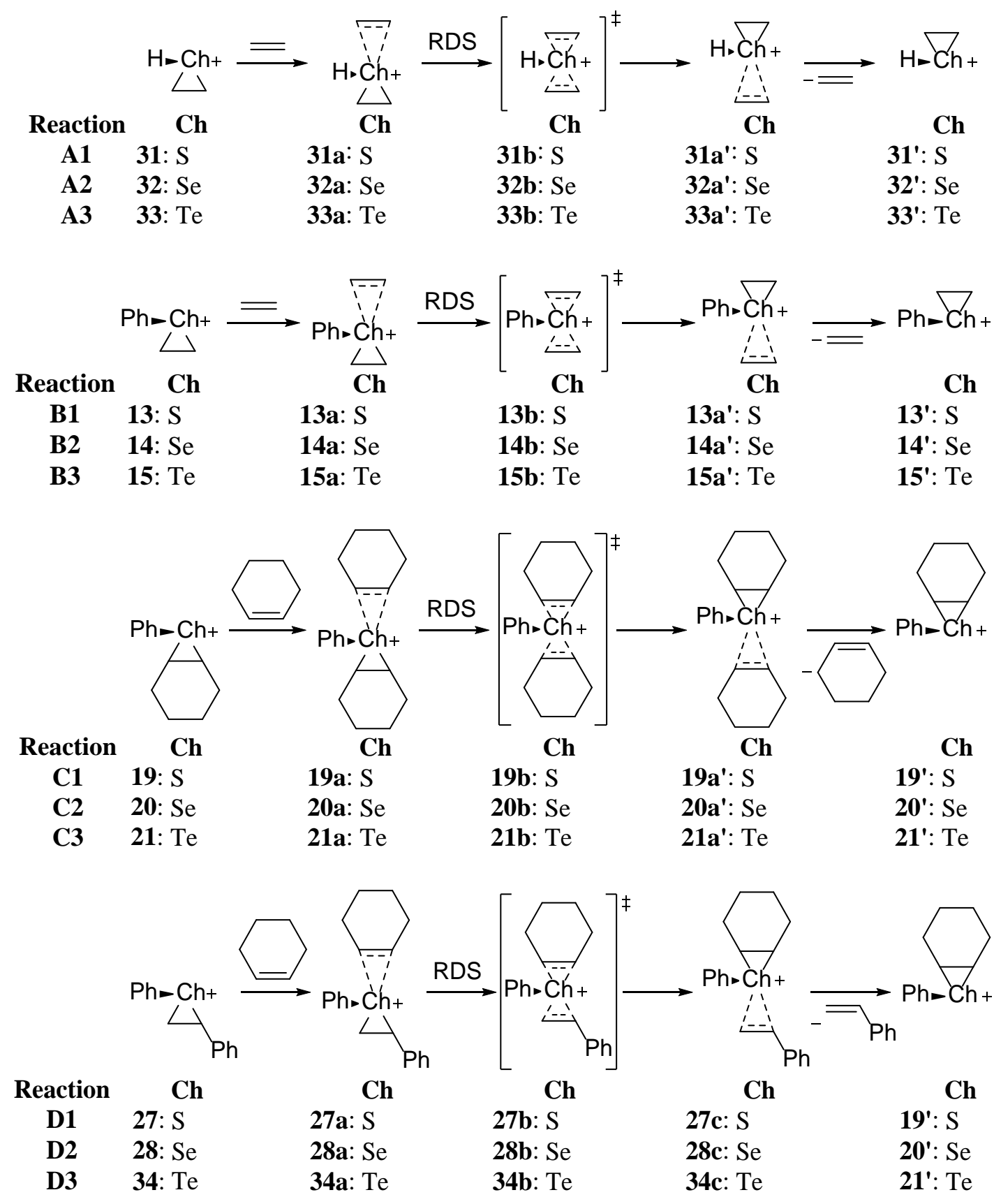

Scheme 4. $\pi$-Ligand exchange identity (A, B and C) and non-identity (D) reactions of chalcogen iranium ions with the rate determining step (RDS) indicated (based on references 24-26). 


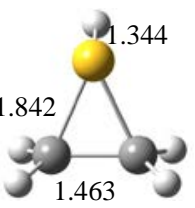

31

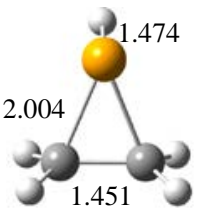

32

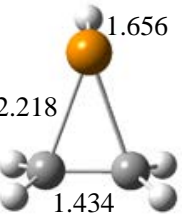

33

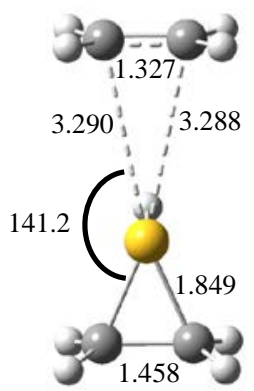

31a (front)

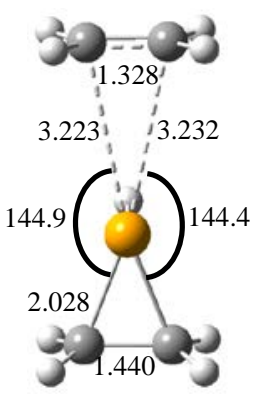

32a (front)

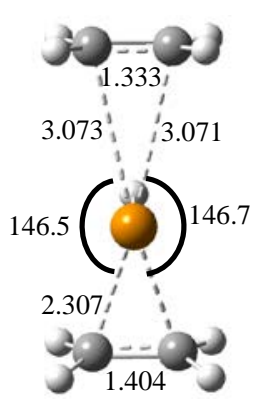

33a (front)

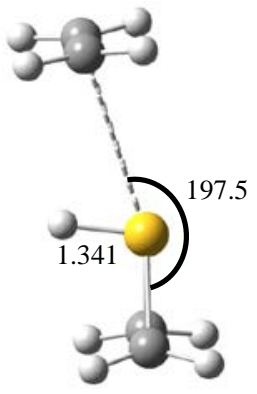

31a (side)

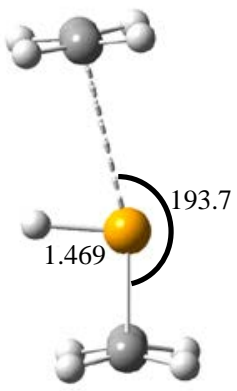

32a (side)

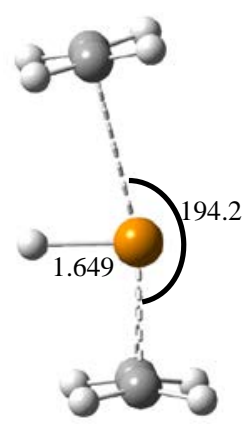

33a (side)
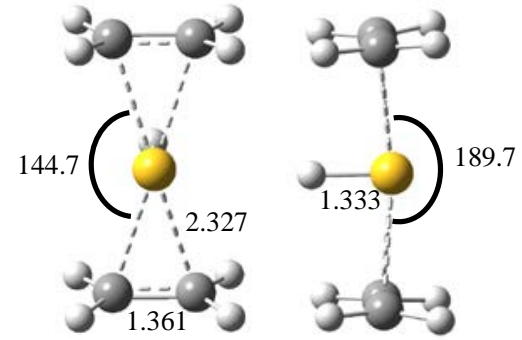

31b (front)
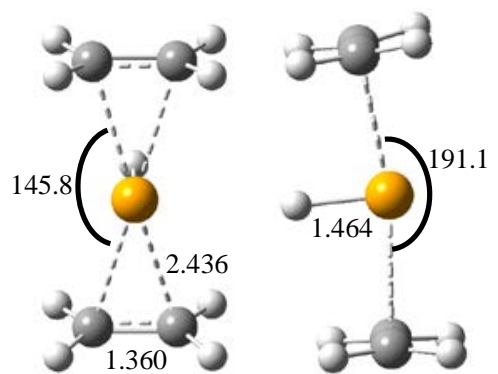

32b (front)

32b (side)

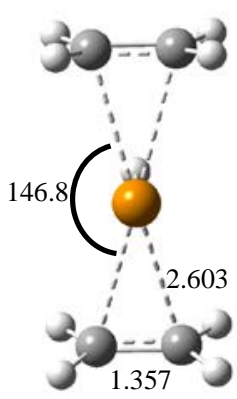

33b (front)

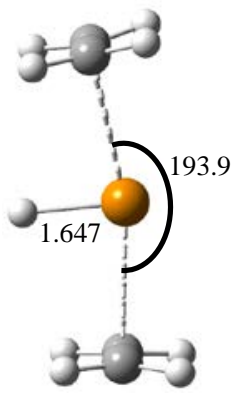

33b (side)

Figure 2. Calculated structures for key species in reactions A1 (top), A2 (middle) and A3 (bottom). Bond lengths in angstrom $(\AA)$, angles in degrees $\left(^{\circ}\right)$. Due to symmetry, not all key bond lengths and angles are given if the same to the third or first decimal place respectively. 


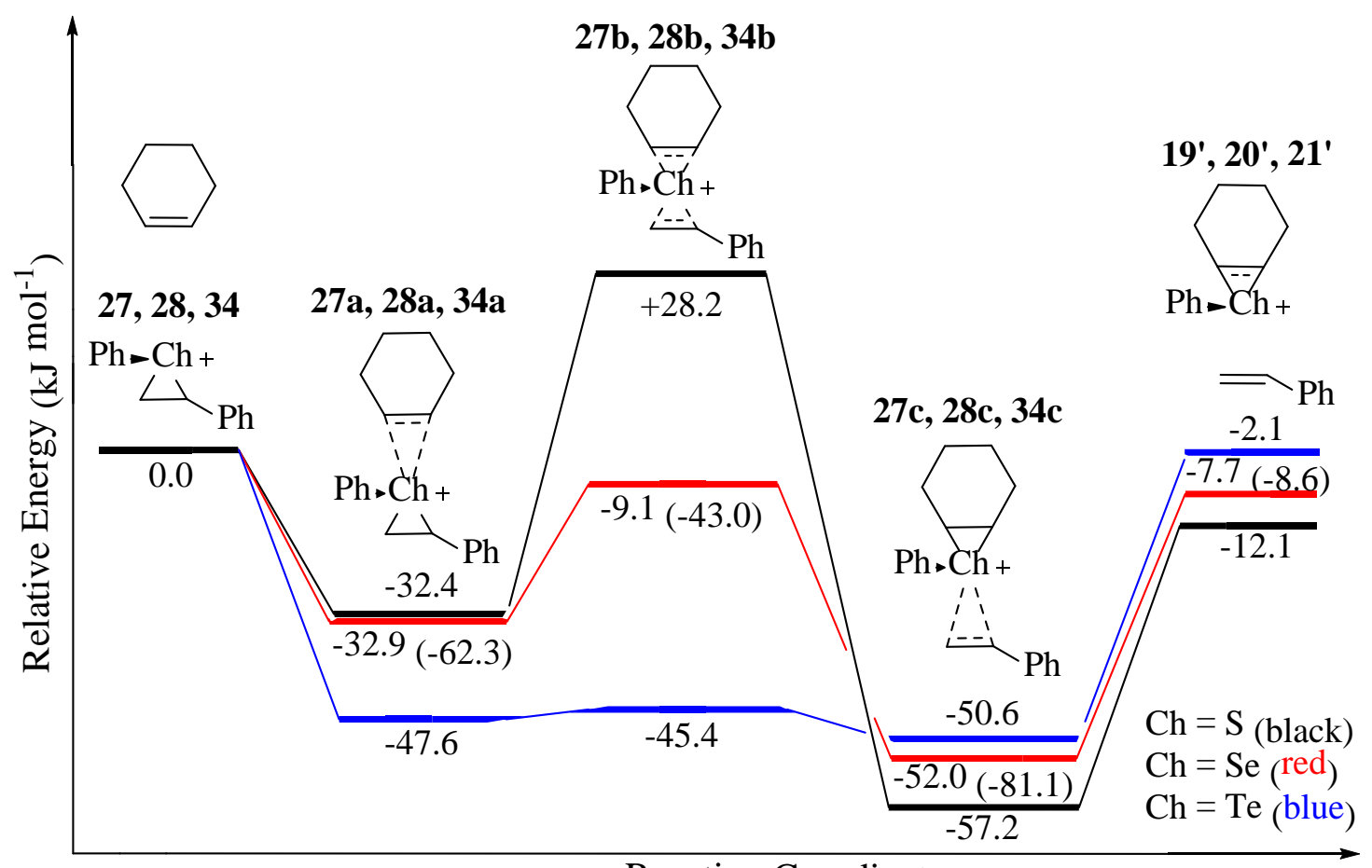

Reaction Coordinate
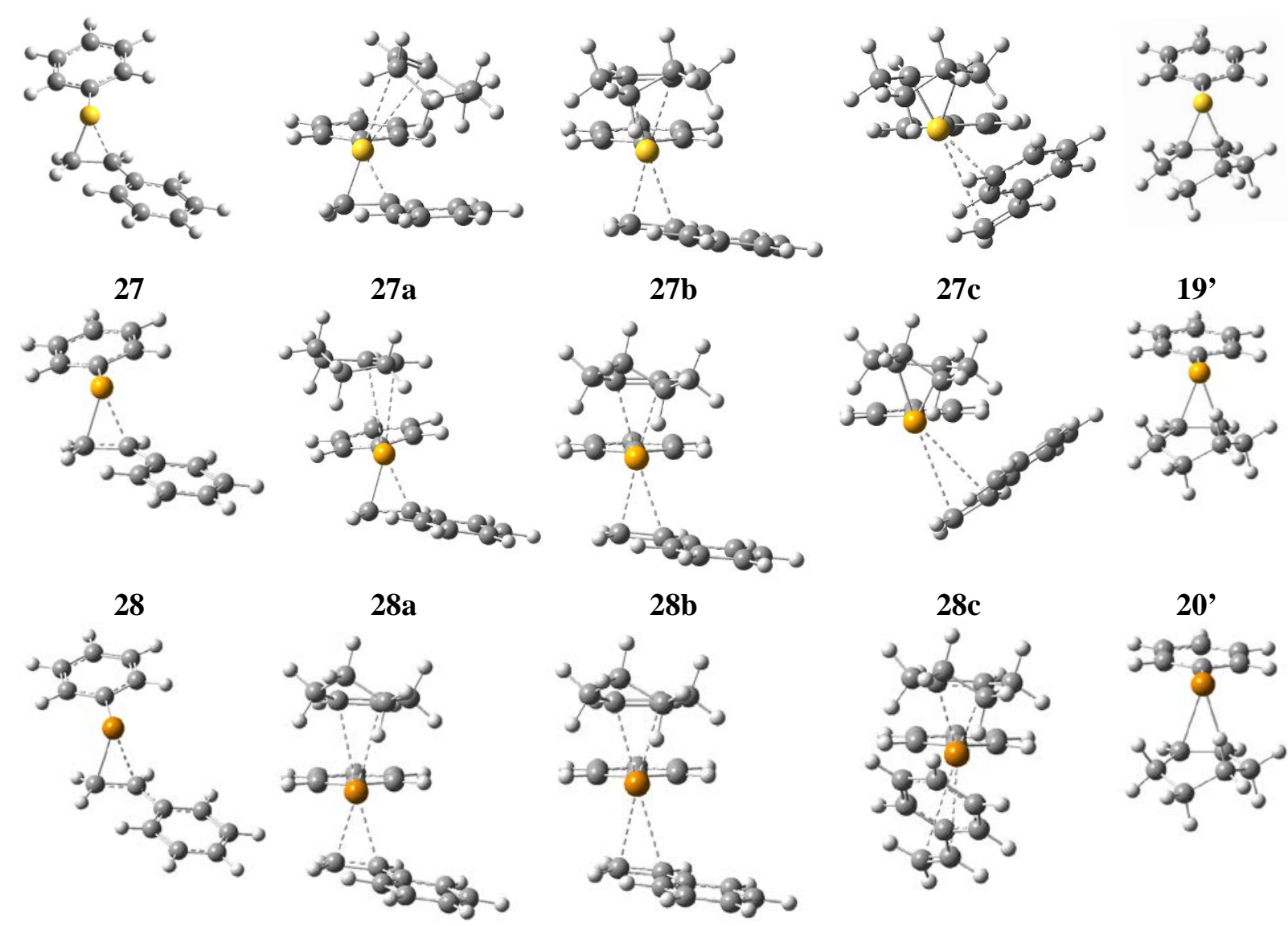

34

34a
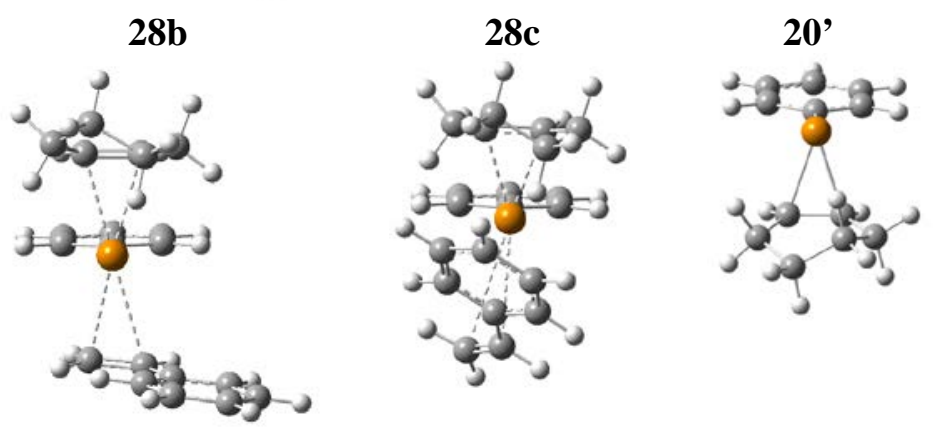

34b

$34 c$

21' 
Figure 3. Relative energy diagram of D1-3 $\pi$-ligand exchange reactions for chalcogen iranium ions 27 (adapted from reference 25), $\mathbf{2 8}$ and $\mathbf{3 4}$ with cyclohexene to afford products 19'-21' (Ch = S - black; $\mathrm{Se}$ - red; Te - blue). Energies given as $\Delta E$ in $\mathrm{kJ} \mathrm{mol}^{-1}$ at M06-2X/def2-TZVP relative to the free reactants. Energies in brackets correspond to previous study of $\mathrm{Ch}=$ Se calculated at M06/6-31+G(d), given as $\Delta E$ at $298 \mathrm{~K}$ in kJ mol$^{-1}$. ${ }^{24}$

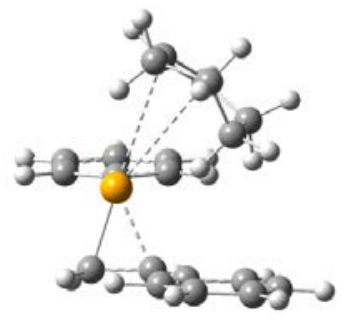

28a'

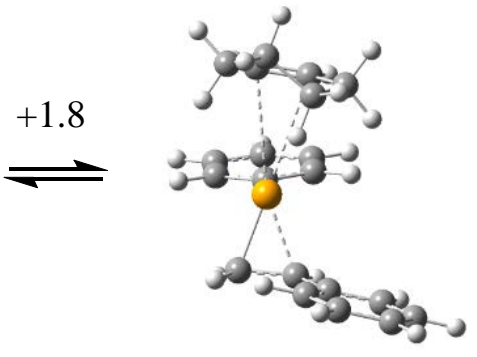

28a”'

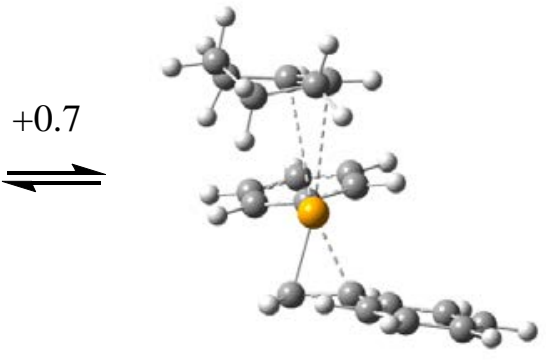

28a

Scheme 5. Isomerisation of 28a' to 28a via transition state 28a'”. Energies given as $\Delta E$ in $\mathrm{kJ} \mathrm{mol}^{-1}$ at M06-2X/def2-TZVP relative to 28a'.

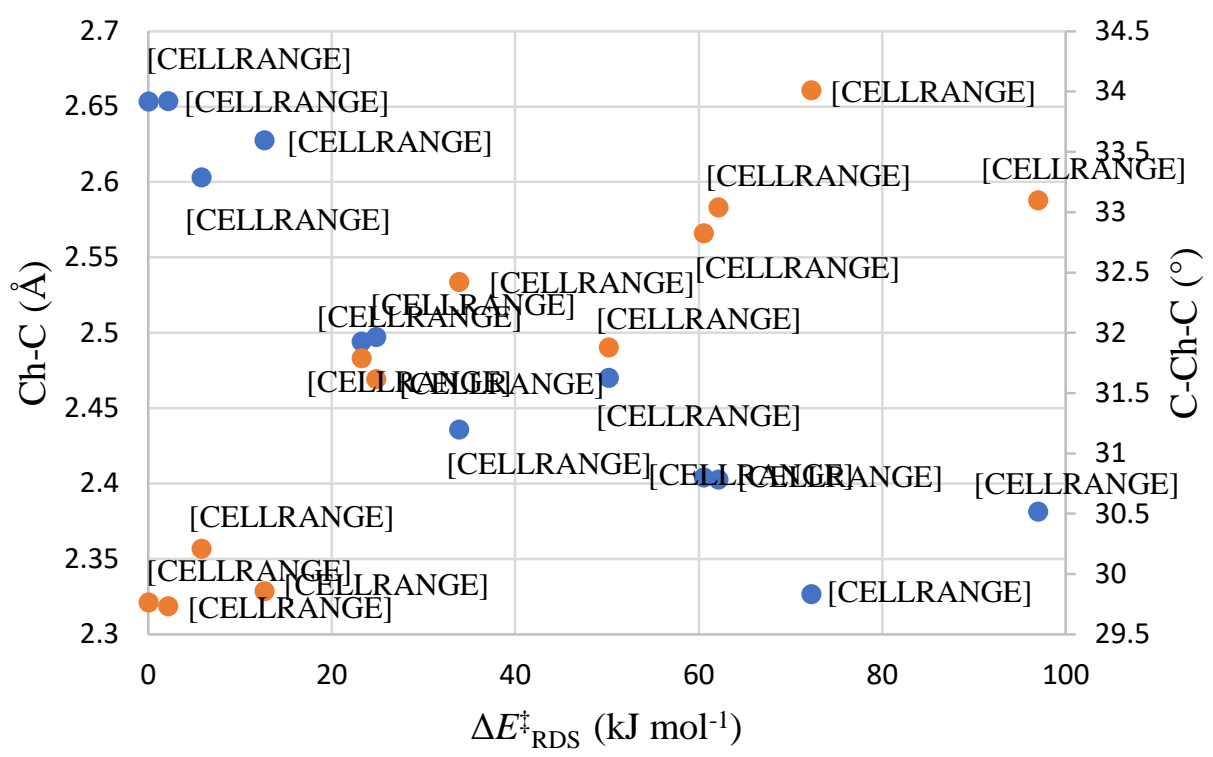

Figure 4. Plot of the average Ch-C bond length in $\AA$ (blue dots, $\mathrm{R}^{2}=0.825$ ) and the average C-Ch-C angle in ${ }^{\circ}$ (orange dots, $\mathrm{R}^{2}=0.808$ ) for transition states in reactions $\mathbf{A}-\mathbf{D}$ against barrier height relative to association complex $\left(\mathrm{kJ} \mathrm{mol}^{-1}\right)$.
$\mathrm{H}-\overline{\mathrm{S}}^{+}$
$\overline{\mathrm{H}-\mathrm{S}^{+}}$
$\mathrm{H}-\overline{\mathrm{Se}}^{+}$
$\overline{\overline{\mathrm{H}-\mathrm{Se}^{+}}}$
H-Te ${ }^{+}$
H- $\overline{\overline{\mathrm{Te}}}+$
$4 \times 1 \overline{\overline{6.4}} \%$
$4 . \overline{\overline{8 \%}}$
$4 \times 16.65 \%$
$4 . \overline{\overline{87 \%}}$
$4 \times \overline{\overline{5.97}} \%$
$12.34 \%$

Figure 5. Selected Lewis structures from natural resonance theory analysis of transition states 31b33b 


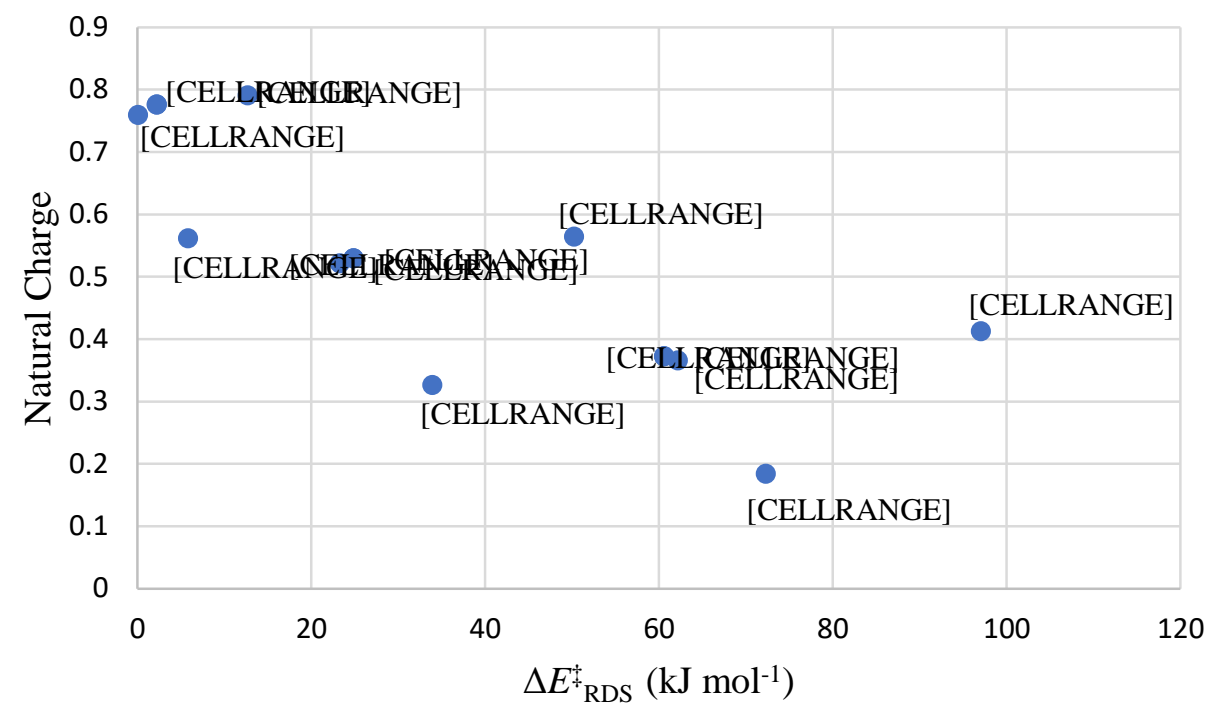

Figure 6. Plot of natural charge on the chalcogen for all transition states against barrier height relative to the association complex $\left(\mathrm{kJ} \mathrm{mol}^{-1}\right)$ with $\mathrm{R}^{2}=0.6318$. 


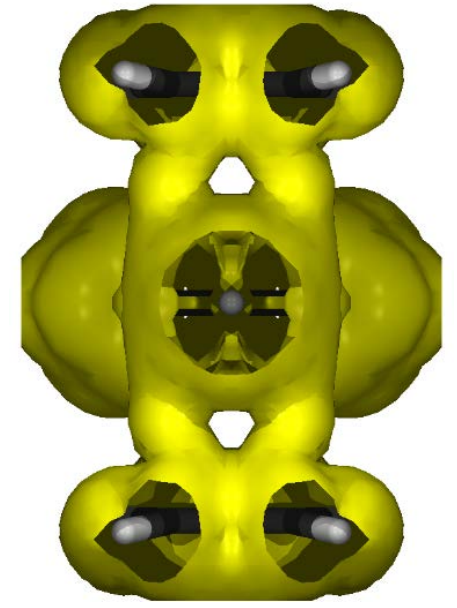

Isosurface $=0.01 \mathrm{au}$

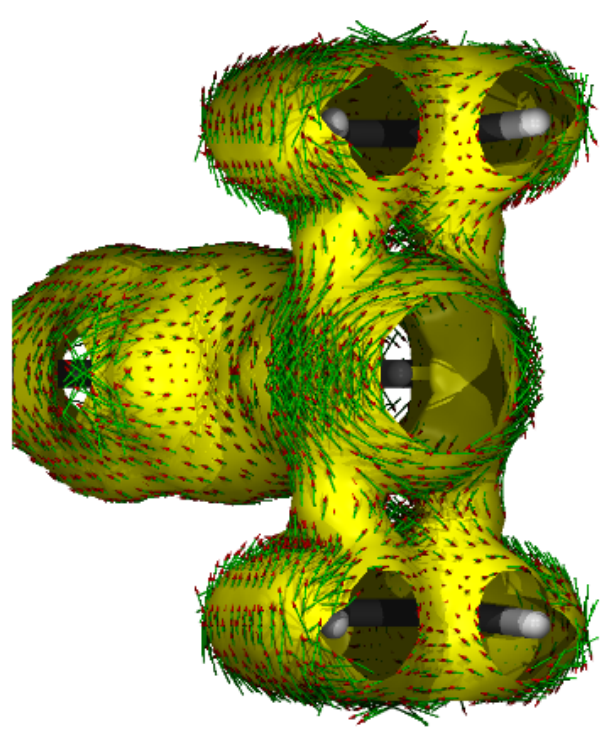

Isosurface $=0.01 \mathrm{au}$
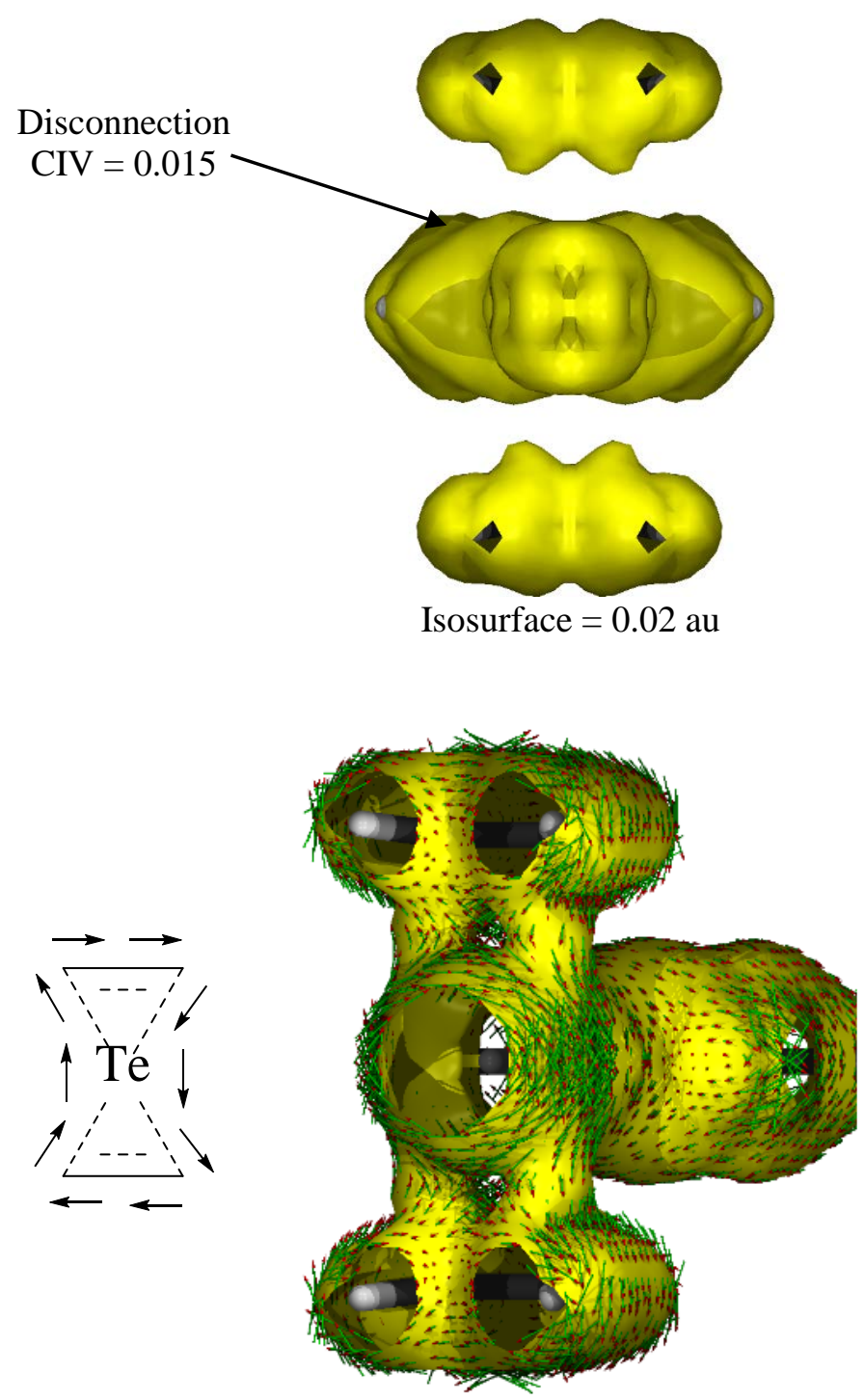

Isosurface $=0.01 \mathrm{au}$

Figure 7. ACID plots at variable isosurface values of transition state $\mathbf{1 5 b}$ from reaction $\mathbf{B} 3$ involving the transfer of the $\mathrm{PhTe}^{+}$moiety between ethenes with all four of the bonds breaking/forming having a CIV value of 0.015 as indicated in the top structures. The current density vectors have been plotted on the two bottom structures to show the direction of the ring current (the right hand side has been rotated $180^{\circ}$ around the $\mathrm{C}=\mathrm{C}_{\text {mid }}-\mathrm{Ch}-\mathrm{C}=\mathrm{C}_{\text {mid }}$ axis) with the diagram in the centre (the phenyl group points into the page and is omitted for clarity) representing the direction of electron flow as black arrows. The direction of the magnetic field lies along the $\mathrm{Ph}-\mathrm{Te}$ axis pointing out of the page. 


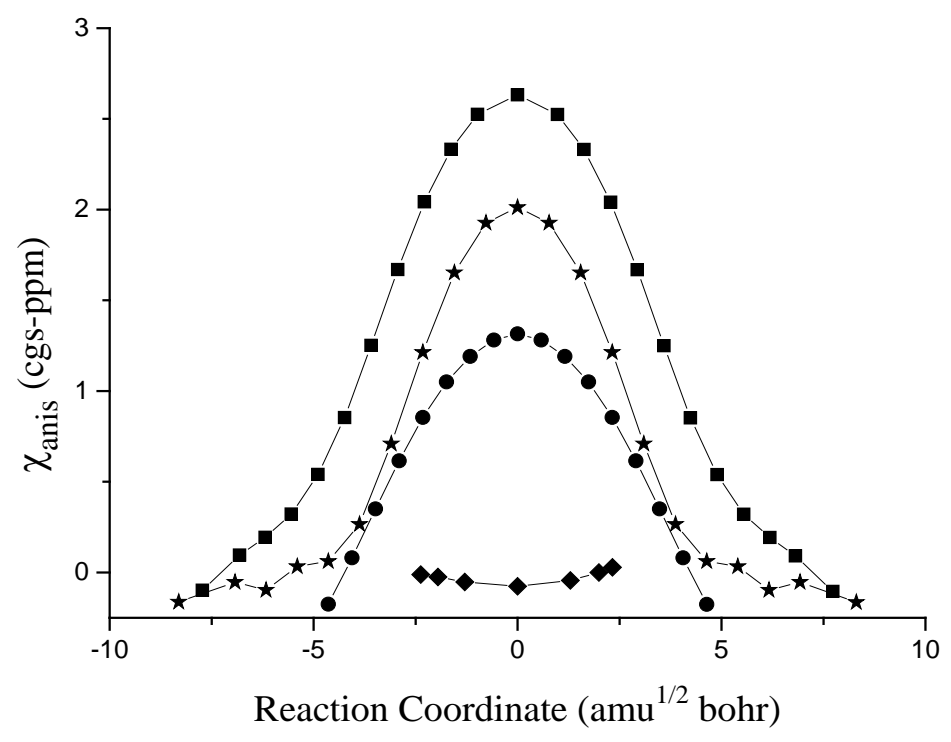

Figure 8. Change in the anisotropy of the magnetic susceptibility, $\chi_{\text {anis, }}$ (cgs-ppm) along the reaction coordinate $\left(\mathrm{amu}^{1 / 2}\right.$ bohr) of identity reactions A1 $(\star)$, A2 $(\mathbf{\bullet}), \mathbf{A 3}(\bullet)$ and $\mathbf{C 3}(\bullet)$ relative to respective association complexes (raw data is collated in Tables S4-7 in the Supporting information).

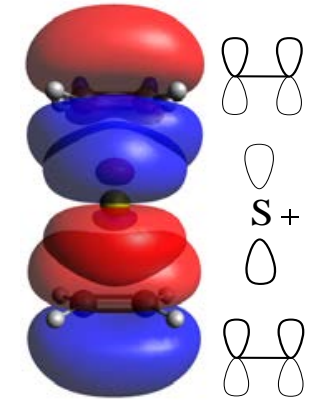

$2 \times \pi_{\mathrm{C}=\mathrm{C}}-\mathrm{p}_{\mathrm{Ch}}^{+}$

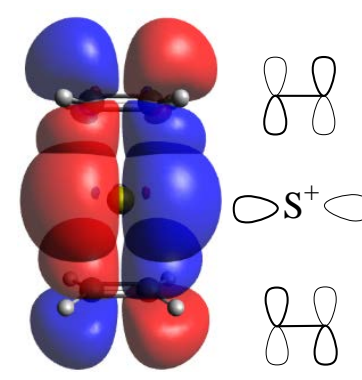

$\mathrm{n}_{\mathrm{Ch}}-\pi^{*}=\mathrm{C}$

Figure 9. Significant natural bond orbital interactions in the sulphur transition state 31b visualised at an isosurface value of 0.02 au. Hydrogens have been excluded in the schematic orbitals for clarity. 


\section{University Library}

\section{- M M I N E R VA A gateway to Melbourne's research publications}

Minerva Access is the Institutional Repository of The University of Melbourne

Author/s:

Brydon, SC;da Silva, G;White, JM

Title:

Evidence that pi-ligand exchange reactions of chalcogen iranium ions proceed via Huckel pseudocoarctate transition states

Date:

2020-12

Citation:

Brydon, S. C., da Silva, G. \& White, J. M. (2020). Evidence that pi-ligand exchange reactions of chalcogen iranium ions proceed via Huckel pseudocoarctate transition states. Journal of Physical Organic Chemistry, 33 (12), https://doi.org/10.1002/poc.4111.

Persistent Link:

http://hdl.handle.net/11343/276018 